\title{
Intercomparison of Cloud Imagery from the DMSP OLS, NOAA AVHRR, GOES VISSR, and Landsat MSS
}

\author{
R. G. ISAACS AND J. C. BARNES \\ Atmospheric and Environmental Research, Inc., Cambridge, MA 02139
}

(Manuscript received 25 November 1986, in final form 16 April 1987)

ABSTRACT

Concurrent visible and infrared imagery from four satellite sensors (DMSP OLS, NOAA AVHRR, GOES VISSR, Landsat MSS) have been intercompared. Inherent differences in observed cloud properties and cloud field analyses are noted due to individual sensor characteristics such as spatial and spectral resolution, solar illumination conditions, and scene/sensor geometry. Specific comparisons made include: GOES to DMSP, NOAA to DMSP, Landsat to DMSP and Landsat to GOES. These satellite imagery comparisons provide guidelines for the analyst to assist in the correct interpretation of cloud properties from different satellite sensors.

\section{Introduction}

Since the first images were collected from space on a routine basis from the TIROS series of meteorological satellites some 25 years ago, satellite technology has evolved to the point where several satellite systems now provide imagery for meteorological and other geophysical purposes. The two that have most directly evolved from TIROS are the polar orbiting (LEOLow Earth Orbit) Air Force DMSP (Defense Meteorological Satellite Program) and civil NOAA systems. The GOES satellites, in geosynchronous (GEO) orbit, also provide imagery on a regular basis, covering the earth's disk every half-hour. The GOES IR sensor resolution is not as good as that of DMSP or NOAA and observations are not useful at high latitudes; however, with the introduction of improved processing techniques to display cloud motion in sequential GOES images, these data are gaining increasing use by forecasters. An evaluation of observations from satellites for the study and prediction of mesoscale and cyclone events has recently been published by Shenk et al. (1987). In this paper, which provides an excellent review of the current status of satellite observations, the authors point out that geosynchronous measurements are going to be the principal data source for mesoscale and cyclone events.

In the early 1970s the first of the Landsat series of earth resources satellites was orbited. Although not designed for meteorological purposes, Landsat has nevertheless provided imagery useful for cloud studies. Landsat data are not useful for operational analysis because of limited spatial coverage and repeat frequency, but the very high resolution of the images enables cloud features not seen by other satellites to be detected.
Each of these satellite systems, all of which provide visible and thermal infrared cloud imagery, has differing orbital and sensor characteristics, such as platform altitude, time of passage, repeat cycle, spatial coverage, sensor resolution, wavelength sensitivity, and physical calibration. Because of these differences it is difficult to compare the imagery from the different systems even though analysts often use data from more than one satellite. For example, DMSP and GOES, or NOAA and GOES, are often used in combination for operational cloud analysis.

The primary goal of this study was to develop techniques to aid in the correct interpretation of satellite cloud imagery datasets from various sensor systems. By quantifying the differences in cloud signatures observed from various sensors, it will eventually be possible to circumvent some of the problems associated with utilizing multiple sensor datasets in the analysis of clouds. Here, the focus was on direct comparison of actual image samples selected to provide as closely as possible, near simultaneous and collocated data from the satellites of interest (i.e., DMSP, NOAA, GOES, Landsat). Based on this approach, identical cloud features could be observed from different sensor platforms and the characteristic differences in their appearance due to instrumental factors qualitatively noted. The specific data comparisons were paired as GOES to DMSP, NOAA to DMSP, Landsat to DMSP, and Landsat to GOES.

Studies of certain characteristics of satellite sensors with regard to estimating cloud cover have been carried out for some time. For example, Shenk and Salomonson (1972) simulated various cloud distributions and sizes to investigate the effects of sensor spatial resolution on estimates of cloud cover. They found that spatial resolution had a strong effect on estimates of percentage 
cloud cover, but that estimates could be improved substantially using a nomogram that took into account the ratio of areal cloud size to areal resolution size.

In other previous studies, comparisons have been made between imagery from two different satellite sensors for observation of specific geophysical parameters. One such study involved the comparison of DMSP and Landsat imagery in which anomalous gray-shade patterns associated with low visibility in light fog or haze could be detected (Barnes et al., 1979a; Fett and Isaacs, 1979). The purpose of the investigation was to use the Landsat MSS data (four spectral bands) to determine which wavelengths within the overall DMSP range $(0.4-1.1 \mu \mathrm{m})$ are responsible for the anomalous gray-shade patterns. The comparisons indicated that the relative contributions of energy from the different spectral intervals comprising the total DMSP response must be considered rather than the response function alone. It was also concluded that the differing spatial resolutions of the sensors are an important factor when viewing atmospheric features with continuously varying intensity response, such as haze or a developing cloud:

Data from different satellite sensors have also been compared in an evaluation of the capabilities of satellite imagery for monitoring regional air pollution episodes (Barnes et al., 1979b). In this study, samples of visible imagery from NOAA/VHRR (the sensor flown prior to the AVHRR), GOES, and Landsat were compared for a day on which a haze episode occurred. All of the differing satellite/sensor characteristics, such as spectral sensitivity, viewing angle in relation to the sun angle, and spatial resolution were taken into account in the comparative analysis. The results demonstrated that for monitoring pollution episodes, GOES was the most useful because of its frequent observations, thus enabling a region to be viewed at varying sun angles.

Two geophysical parameters that have been mapped extensively using imagery from various satellites are the earth's snow and ice cover. Handbooks for snow mapping provide guidelines on the interpretation and discuss the advantages and disadvantages of imagery from all available satellites (Bowley et al., 1979). In a related investigation of Heat Capacity Mapping Mission (HCMM) thermal data for snow hydrology (Barnes et al., 1981), comparative snow maps were prepared from HCMM, NOAA/AVHRR, and Landsat imagery and digitized data; the relative resolutions and other characteristics of the different sensors were evaluated. In this study, as well as in all of the above-cited studies, the effects of sensor characteristics such as spectral and spatial resolution, viewing geometry, and sensitivity were found to impact significantly the accuracy of the analyses.

Another area where data from various satellites have been incorporated is the compilation of cloud climatologies. It has been recognized for some time that improved global cloud climatologies can only be accom- plished using satellite data, usually from several space platforms. The three-dimensional (3-D) nephanalysis developed by the Air Force has been used operationally for several years, as well as having been used extensively in comparative studies. The 3-D nephanalysis model [now referred to by the Air Force as the real-time (RT) nephanalysis], which is described in reports such as Bunting et al. (1983) and Hughes and Henderson-Sellers (1985), provides the only current global cloud archive.

The requirement for an accurate global cloud climatology has now been internationally recognized by the establishment of the International Satellite Cloud Climatology Project (ISCCP), a five-year project undertaken in 1983 (Schiffer and Rossow, 1983, 1985). It is important for the success of the ISCCP to develop algorithms for the accurate retrieval of cloud information from satellites and thus to understand the inherent differences in the various satellite systems.

\section{Characteristics of imaging sensors}

\section{a. DMSP OLS}

The DMSP (Defense Meteorological Satellite Program) has provided polar-orbiting satellite data to the military services for more than 20 years. The program was declassified in the early 1970 s, and archived DMSP imagery has been made available to nonmilitary users since that time. In recent years, the DMSP and civilian polar-orbiting satellite systems have become more similar in many respects as the result of an attempt to attain some uniformity between the two systems and thus reduce the costs of developing and launching complex satellite systems. The DMSP system is described in several references including Rivers and Arnold (1982), Kaehn (1982), and Haig (1982). The current DMSP system is the Block 5D spacecraft, which transmits direct readout data to transportable terminals deployed worldwide. The platform and sensor characteristics for the DMSP and the other imaging systems are summarized in Tables 1 and 2, respectively.

The OLS (Operational Linescan System), first flown in 1976 on the Block 5D spacecraft, is the primary meteorological sensor of the DMSP (Spangler, 1974). Current plans call for the OLS to continue to be included in the sensor package at least until the 1990 timeframe. The OLS is a two-channel radiometer, but its operation is somewhat different from that of other radiometers (such as the TIROS/AVHRR) in that the mirror oscillates rather than rotates. This back-andforth sinusoidal motion of the optical telescope system moves the instantaneous field of view of the detectors across the satellite subtrack, with maximum scanning velocity at nadir and reversals at the ends of the scans. The detector size of the optics is dynamically changed to reduce the field of view near the end of each scan, thus maintaining an essentially unchanged footprint size on Earth's surface. The gain of the sensor is also 
TABLE 1. Operational platform characteristics.

\begin{tabular}{|c|c|c|c|c|}
\hline & DMSP & NOAA & GOES & Landsat \\
\hline Orbit & LEO & LEO & GEO & LEO \\
\hline Altitude $(\mathrm{km})$ & 833 & 854 & 36000 & 705 \\
\hline Approximate time of equator crossing & $0000 / 1200^{*}$ & $0300 / 1500$ & n/a & 0945 \\
\hline (LST) & $0700 / 1900$ & $0730 / 1930$ & & \\
\hline Period (min) & 101 & 102 & $\mathbf{n} / \mathbf{a}$ & 98.9 \\
\hline Inclination (deg) & 98.7 & 98.9 & $\mathbf{n} / \mathbf{a}$ & 98.2 \\
\hline Latitude range (deg) & $\mathrm{n} / \mathrm{a}$ & n/a & $60^{\circ} \mathrm{N} / 60^{\circ} \mathrm{S}$ & $\mathrm{n} / \mathrm{a}$ \\
\hline Data swath $(\mathrm{km})$ & 2560 & 2240 & earth disk & 185 \\
\hline Repeat cycle & $12 \mathrm{~h}$ & $12 \mathrm{~h}$ & $1 / 2 \mathbf{h}^{\dagger}$ & 16 days \\
\hline
\end{tabular}

* May vary, but usually in dawn/dusk and noon/midnight orbits.

${ }^{\dagger}$ Data for selected portions of the disk can be collected more frequently.

adjusted along the scan line to compensate for larger variations in the reflected light level as the satellite crosses the terminator. Furthermore, through use of a photomultiplier tube, it is possible for the OLS to collect reflected visible radiation at night, with illumination as low as that corresponding to a quarter moon.

The OLS visible sensor (" $L$ " data) covers a relatively broad spectral band $(0.4-1.1 \mu \mathrm{m})$. The IR ("T" data) bandwidth is $10.4-12.5 \mu \mathrm{m}$ (before June 1979 , this bandwidth was $8.0-13.0 \mu \mathrm{m})$. Direct readout data at "fine" $(\mathrm{F})$ resolution $(0.6 \mathrm{~km})$ and "smoothed" $(\mathrm{S})$ resolution $(2.8 \mathrm{~km})$ can be received at the transportable terminals; data can also be recorded onboard the spacecraft at the smoothed resolution for transmission to the central receiving station (low light level nighttime visible data are at $2.8 \mathrm{~km}$ resolution). The main features of the OLS are listed in Table 2. The meteorological interpretation of the Block 5D OLS and earlier DMSP imagery is discussed in reports by Brandli (1976) and Fett and Mitchell (1977).

\section{b. NOAA AVHRR}

The current civilian polar-orbiting satellites (the TIROS-N/NOAA A-G Series) have been operational since late 1978 and carry an instrument package consisting of the AVHRR (Advanced Very High Resolution Radiometer) and the TOVS (TIROS Operational Vertical Sounder). A detailed description of the instruments can be found in Schwalb (1978) and NOAA (1981).

The AVHRR is a 5-channel radiometer with two channels in the visible and three in the thermal infrared. The two visible channels fall within the broader wavelength band of the DMSP/OLS (see Table 1 for orbital characteristics of the spacecraft and Table 2 for characteristics of the sensors). The ground resolution of the AVHRR at nadir is $1.1 \mathrm{~km}$; at a satellite altitude of $850 \mathrm{~km}$, the data swath is $2240 \mathrm{~km}$. Data from the AVHRR instrument are available from the satellite in four operational modes:

TABLE 2. Characteristics of current meteorological imagers.

\begin{tabular}{|c|c|c|c|c|c|}
\hline & \multicolumn{5}{|c|}{ Sensor } \\
\hline & OLS & AVHRR & VAS & TM & MSS \\
\hline Spacecraft & DMSP & NOAA & GOES & Landsat & Landsat \\
\hline Orbit & Polar (LEO) & Polar (LEO) & GEO & Polar (LEO) & Polar (LEO) \\
\hline \multicolumn{6}{|c|}{ Wavelength $(\mu \mathrm{m})$} \\
\hline \multicolumn{6}{|c|}{ Channel } \\
\hline 1 & $0.4-1.10$ & $0.58-0.68$ & $0.55-0.70 \#$ & $0.45-0.52$ & $0.50-0.60$ \\
\hline 2 & $10.4-12.5^{*}$ & $0.725-1.1$ & $10.5-12.5$ & $0.52-0.60$ & $0.60-0.70$ \\
\hline 3 & & $3.55-3.93$ & & $0.63-0.69$ & $0.70-0.80$ \\
\hline 4 & & $10.5-11.3$ & & $0.76-0.90$ & $0.80-1.10$ \\
\hline 5 & & $11.5-12.5$ & & $1.55-1.75$ & \\
\hline 6 & & & & $2.08-2.35$ & \\
\hline 7 & & & & $10.40-12.50$ & \\
\hline \multicolumn{6}{|c|}{ Resolution at } \\
\hline \multicolumn{6}{|c|}{ Nadir (meters) } \\
\hline Visible & $600,2800^{\dagger}$ & 1100 & 800 & 30 & 80 \\
\hline IR & 600,2800 & 1100 & 7000 & 120 & \\
\hline
\end{tabular}

* OLS IR wavelength was 8.0-13.0 $\mu \mathrm{m}$ before June 1979.

$\dagger 600 \mathrm{~m}$ at fine resolution, $2800 \mathrm{~m}$ at smoothed resolution.

\# Wavelengths given are for the VISSR mode of operation of the VAS. 
- APT (Automatic Picture Transmission): direct readout to worldwide ground stations of the APT visible and infrared data degraded to $4 \mathrm{~km}$ resolution.

- HRPT (High Resolution Picture Transmission): direct readout (S-band) to worldwide ground stations of the HRPT data for all spectral channels $(1.1 \mathrm{~km}$ resolution).

- GAC (Global Area Coverage): global on-board recording of $4-\mathrm{km}$ resolution data from all spectral channels for commanded readout for processing in the NOAA central computer facility at Suitland, Maryland.

- LAC (Local Area Coverage): on-board recording of data from selected portions of each orbit at $1.1 \mathrm{~km}$ resolution and all spectral channels for central processing.

\section{c. GOES VISSR}

The existing civilian geosynchronous satellites (SMS/ GOES series) carry the VAS (VISSR Atmospheric Sounder) which is an improved version of the VISSR (Visible Infrared Spin Scan Radiometer) carried on the earlier SMS and GOES satellites. GOES-4, launched in September 1980, was the first to carry the VAS and thus is considered to be the first of the second generation of operational, geosynchronous meteorological satellites. The VAS is described in reports by Santa Barbara Research Center (1978) and Cornillon (1982).

The improvements in the instrument consist of the addition of several infrared detectors, the addition of an infrared filter wheel in the optical train, and the capability of operating the instrument in several different modes. The filter wheel consists of 12 filters, any one of which may be placed in the optical path; the filtered radiation is then directed to one of three pairs of infrared detectors. Scanning is achieved by rotation of the satellite; the filter wheel is not rotated while Earth is being scanned. The VAS may be operated in three modes: the VISSR mode, the MSI (Multispectral Imaging) mode, and the DS (Dwell) or Sounding mode.

The VAS has been operated primarily in the VISSR mode; the MSI mode has not been used extensively because of limited ground-station capability to receive these data (i.e., the down-link for MSI is different than that for VISSR). The instrument has been operated in the DS mode to collect data for comparative studies with other atmospheric sounders and radiosonde data.

In the VISSR mode, the data collected are similar to that of the earlier GOES VISSR instruments. The visible channel $(0.55-0.70 \mu \mathrm{m})$ has a resolution of 0.8 $\mathrm{km}$ by $0.8 \mathrm{~km}$ at nadir, whereas the thermal infrared channel $(10.5-12.6 \mu \mathrm{m})$ has a resolution of $7 \mathrm{~km}$, somewhat improved over that of the earlier GOES. The GOES imagery is routinely processed to cover the full earth disk or certain sectors. The effective resolutions of the resulting images varies; the North America sector (WB1) has a resolution (visible data) of $2 \mathrm{~km}$ whereas the eastern United States sector (DB5) is at 1 km (Dismachek et al., 1980). Data for the complete earth disk can be collected and transmitted every 30 minutes; data for selected portions of the disk can be collected more frequently.

\section{d. Landsat MSS}

The Landsat series of satellites, the first of which was launched in 1972, has been designed primarily to view Earth's surface rather than Earth's clouds. This is in contrast to meteorological operational satellite systems, such as the polar-orbiting NOAA and DMSP satellites and the geosynchronous GOES satellites, which are described in the preceding sections. Nevertheless, as Landsat data were accumulated, it became obvious that the images also displayed a considerable amount of information relevant to meteorology. One of the first investigations directed toward detection of cloud features by Landsat was reported by Feteris et al. (1976). In that study, some 50 Landsat Multispectral Scanner (MSS) scenes were analyzed in photographic format to identify the structure and characteristics of mesoscale cloud features; the types of clouds examined in the Landsat images included cumulus bands, low-level offshore cloud streets, terrain-induced wave clouds, and severe storm clouds. These detailed cloud features cannot be observed in the lower-resolution meteorological satellite imagery; thus, Landsat can be considered as a source of "ground truth" cloud information, which can be useful for interpreting cloud features seen in the other types of satellite data.

All Landsat spacecraft have carried the MSS, which has a resolution an order of magnitude higher than that of the best meteorological satellite sensor $(80 \mathrm{~m}$ vs $0.6 \mathrm{~km}$ for the DMSP fine-resolution data). The MSS, however, views a very narrow swath $(185 \mathrm{~km})$ and provides repeat coverage of the same area only once every 18 days. The MSS has four spectral bands (see Table 2) covering the interval from 0.5 to $1.1 \mu \mathrm{m}$. Thus, the MSS data can be used to simulate narrower band sensors, such as the GOES VISSR $(0.55-0.7 \mu \mathrm{m})$ as well as the broader band (0.4-1.1 $\mu \mathrm{m})$ of the DMSP OLS; the relative response curves of the MSS and DMSP OLS are shown in Fig. 1.

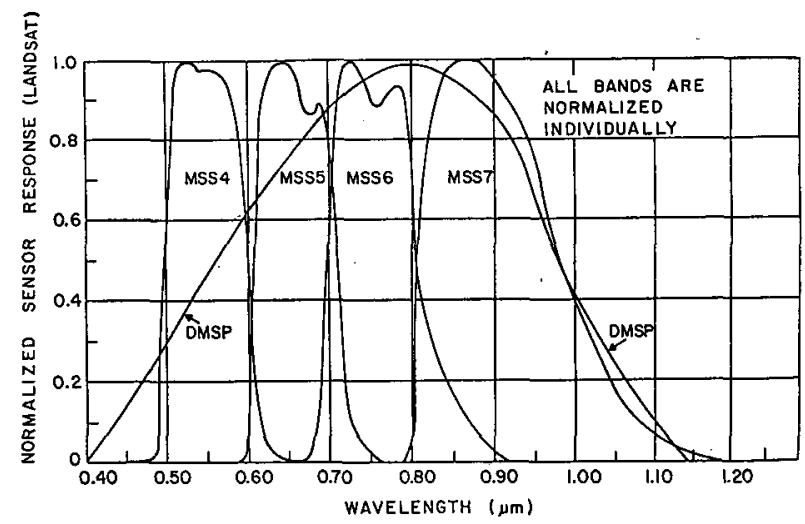

FiG. 1. Landsat and DMSP relative spectral response (Barnes et al., 1979). 
Landsat 4, launched in July 1982, and Landsat 5 carry both the Multispectral Scanner (MSS) and the Thematic Mapper (TM). The TM is designed to achieve finer spatial resolution, sharper spectral separation, improved geometric fidelity, and greater radiometric accuracy and resolution than previous sensors. The instrument and the orbital characteristics of Landsat 4 are described in the Landsat Data Users' Notes (NASA, 1982) and in a paper by Engel and Weinstein (1983). A comparison of the MSS and TM with the other current imagers is shown in Table 2.

\section{Data sample—selection and acquisition}

The acquisition of a concurrent sample of each type of pertinent satellite data was not a trivial task. As described in the previous section, each satellite has unique orbital and sensor characteristics, which may change from time to time as systems are upgraded. Also, data from one of the satellite systems may be missing for a period of time because of satellite failure or may be missing for a particular observation time because of a readout or archival problem. The Air Force and civilian satellite data are not available from the same source; moreover, because DMSP imagery is designed to be used as an operational analysis product, the Air Force does not maintain a data archive.

The initial task of the data selection procedure was to acquire a sample of DMSP images from the civilian archive operated by the Cooperative Institute for Research in Environmental Sciences at the University of Colorado. A sample was selected for a period in early May 1979, covering the central and eastern United States. May 1979 was an opportune time to acquire DMSP data, because three spacecraft were in operation during that period (Block 5D F1, F2 and F3); thus, on some days, images were available for three or more different observation times, increasing the chances for an observation concurrent with an observation from another type of satellite. The initial DMSP data sample was then reviewed to select days with good quality images and distinctive cloud features.

The second step was to acquire GOES and NOAA imagery for the days for which DMSP imagery had been selected. Both types of data are archived at the NOAA Satellite Data Services Division in Washington, DC. Acquisition of GOES images concurrent with the DMSP observations was not a problem since GOES data are archived at half-hourly or, at worst, hourly intervals. NOAA AVHRR images covering the same portions of the United States were also acquired for each day of the sample period. Because of the orbital characteristics of the two systems, however, it was not possible to acquire concurrent NOAA and DMSP data; the NOAA observation time was three to four hours later than the DMSP observation.

The final step in the acquisition of a usable sample for imagery intercomparison was to initiate a search for Landsat data. Although Landsat has a repeat cycle over the same area of only once every 18 days, an orbit covering some portion of the eastern United States (185 $\mathrm{km}$ wide swath) should exist every day. In May 1979, the chances of Landsat coverage were increased, because both Landsat 2 and Landsat 3 were in operation. A data search for the sample period was initiated through EOSAT (the private sector company now operating the nation's Earth Resources Satellite Program), and a listing was received of the orbits for each day. These orbits were in turn plotted on the GOES and DMSP images, and scenes were selected for areas with distinctive cloud features on the orbits most nearly concurrent with GOES and DMSP observation times (with observations from more than one DMSP spacecraft available, it was possible to find some cases where the DMSP pass was within one hour or less of the Landsat midmorning overpass time). Because of cost considerations, images were ordered for only one spectral band (MSS Band 5) for a limited number of Landsat scenes; after reviewing the images, all four MSS bands were ordered for two scenes. Correlative meteorological data were also acquired for the sample period; in addition to surface and upper-air charts, hourly surface observations for reporting stations within the areas of Landsat coverage were obtained.

\section{Data intercomparison-analysis of imagery}

Because DMSP OLS data received at transportable terminals are used operationally only in imagery format, as are most NOAA AVHRR and GOES data at National Weather Service forecast centers, satellite data intercomparison carried out in this study was devoted primarily to the analysis of imagery. The results of the analysis thus provide guidelines for interpretation of the data products most familiar to field personnel. Because of several factors, however, analysis of imagery provides only a qualitative intercomparison of satellite sensors; these factors are discussed in section 4a.

The intercomparison and analysis of imagery was undertaken in two phases. Under the first phase, the results of which are presented in section $4 b$, overall cloud features in DMSP, GOES, and NOAA imagery are intercompared. This analysis is primarily a comparison between GOES and DMSP because of the availability of several excellent, nearly concurrent datasets. This phase of the imagery analysis also provides an opportunity for a NOAA and DMSP intercomparison, as best possible considering the inherent time interval between the observations. Several types of cloud features are examined over the broad areas covered by the DMSP, GOES, and NOAA images.

In the second phase of the imagery analysis, presented in section $4 \mathrm{c}$, a more detailed analysis of specific cloud features over limited areas was undertaken for cases in which Landsat coverage was additionally available. These datasets provide the opportunity for intercomparison of Landsat to DMSP and Landsat to GOES, as well as GOES to DMSP, for the limited areas. 
In these cases, Landsat provides information on cloud structure far more detailed than possible from the other sensors.

\section{a. Considerations for imagery intercomparison}

Several factors which make quantitative intercomparison difficult must be taken into consideration when comparing imagery from different satellite systems. The first consideration when working with DMSP data is that the archived imagery may not be a consistent set of data. This is because DMSP is treated as an operational analysis product and is not designed for use as a research tool.

The DMSP platform and sensor characteristics of the OLS system are described in section 2a. At the receiving sites, various enhancement curves can be used to produce hard copy images from the stored real-time readout data tapes. In the interpretive handbook by Fett and Mitchell (1977), the various mapping curves are shown and are discussed in detail (Fig. 2). For example, an enhancement curve may be applied to enhance cloud features (more gray levels at high reflectances) or to enhance subtle cloud or terrain features (more gray levels at the lower reflectances). Since the original data tapes are not saved, and there may not be documentation on which type of enhancement curve was used to produce a certain image, the images in the DMSP archives do not comprise a consistent dataset. Enhancement curves are also used to produce imagery from other sensor systems, such as the GOES IR data; however, documentation on the enhancement is usually available with the imagery.

Another important consideration is that satellite images are photographic products and thus are subject to the variations inherent in photographic processing.

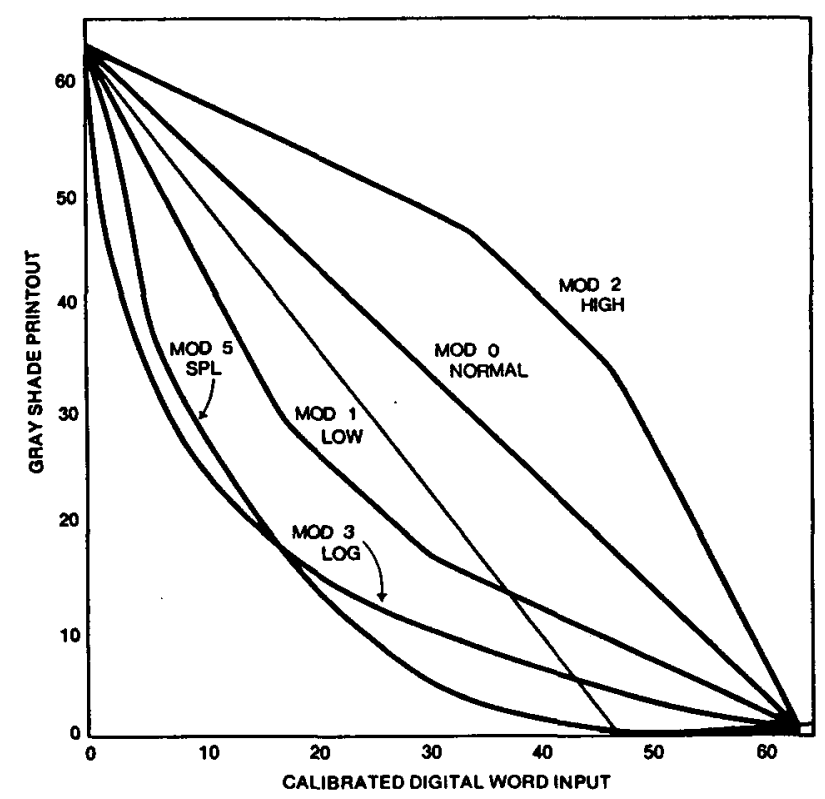

FIG. 2. DMSP OLS enhancement curves (Fett and Mitchell, 1979).
An example of the impact of processing differences on a DMSP image is shown in Figs. $3 a$ and $3 b$. The two images shown in this figure are two photographic copies made from the same archival print (ordered at different times with no processing instructions given). The two prints are obviously quite different, with the image shown in Fig. 3a being overall significantly brighter than that shown in $3 \mathrm{~b}$. The second image (b) contains considerably more detail in the larger cloud masses, such as those to the west of Florida, as some of these features are saturated in the first image (a); on the other hand, terrain features and some thin clouds are more difficult to detect in (b) than in (a). Saturation increases the apparent percentage cloud cover. This can be seen in the cloud cover in several areas, such as between Florida and the Yucutan and to the west of Lake Michigan; in these areas, where the true cloud cover is broken, it appears overcast as a result of the saturation in Fig. 3a. These two prints could be considered as simulations of different enhancement curves, with one being a product to enhance terrain and subtle cloud features and the other to enhance brighter clouds.

Other considerations when analyzing imagery include variation in imagery format and image distortion. The DMSP OLS can be presented as fine (LF, TF) or smoothed (LS, TS) resolution data. Similarly, GOES data can be presented in various formats ranging from full disk, to North America (WB1), to a sectorized image such as the eastern United States (DB5); each of these formats has different resolution. The GOES images have increasing distortion with latitude, and the NOAA AVHRR images are displayed without edge distortion removed (edge distortion is removed in DMSP images). Also, since Landsat has a gain level set for viewing terrain, clouds tend to saturate quickly in Landsat images.

Even when all influencing factors are taken into consideration, identifying and locating the same cloud feature in two different images may be difficult. Although large cloud masses may be easy to identify, specific cloud elements, such as along the edge of a larger cloud mass, may be more difficult; this may be a particular problem when comparing Landsat with meteorological satellite data because of the fine scale of the cloud features viewed at Landsat resolution. Cloud elements may also undergo considerable change over relatively short time intervals between observations. In this regard, cloud size is an important factor, with smaller cloud elements (diameter $\leqslant 2 \mathrm{~km}$ ) likely to undergo more rapid changes; convection-type clouds over land also tend to change more rapidly than clouds over water. Thus, the time difference between images will strongly affect identification of the same cloud feature.

\section{b. Image intercomparison of overall cloud features in DMSP, GOES, and NOAA imagery}

Excellent DMSP and GOES images on 3 May 1979 enable intercomparison of both visible and IR data at 


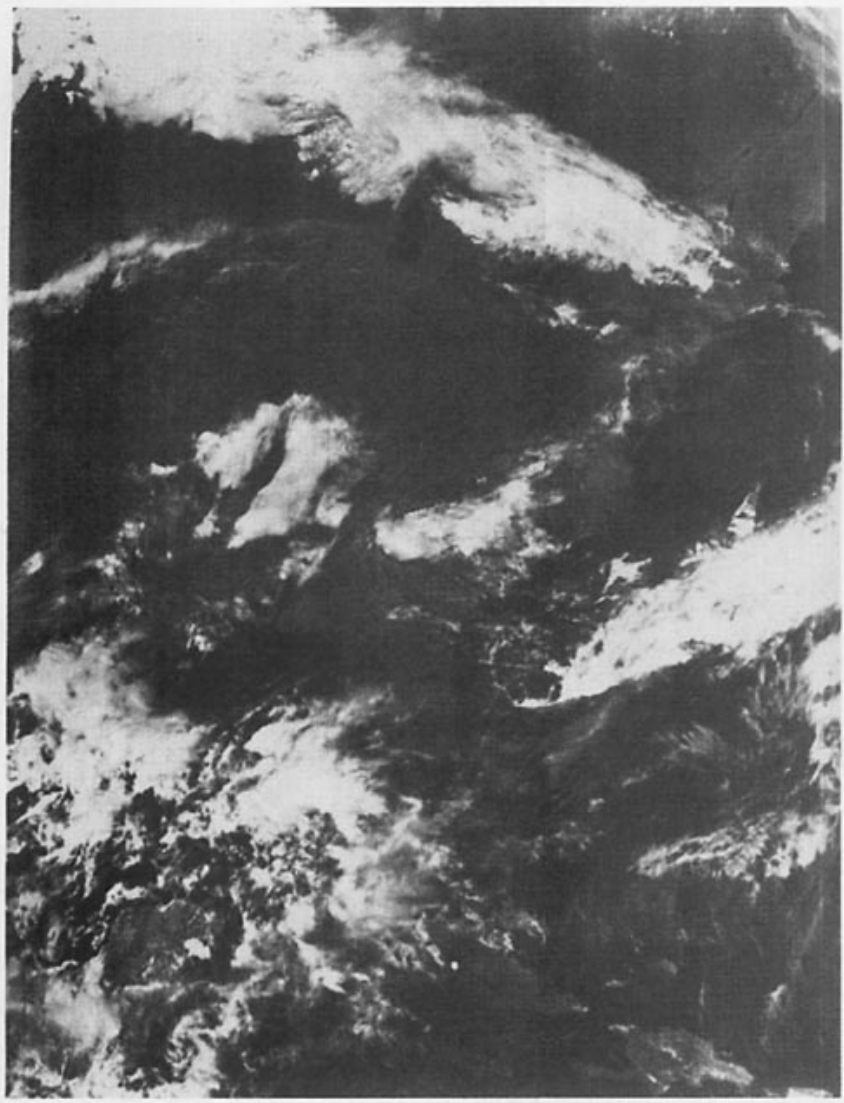

FIG. 3a. DMSP (LS) 1614 UTC 6 May-brighter image.

nearly concurrent times. Also, although the time interval is substantial, it is possible on this date to intercompare NOAA and DMSP data. DMSP smoothed resolution visible and IR images at 1709 UTC are shown in Figs. 4a and 4b; GOES visible and IR images at nearly the same time (1700 UTC) are shown in Figs. $5 \mathrm{a}$ and $5 \mathrm{~b}$. The time given on the GOES image (1700 UTC) is the start time at the top of the image. Since it takes the GOES VAS 18 minutes to scan the complete earth disk, the time of the scan as it reaches the central United States would be about 1705 UTC. The time comparison between the DMSP and GOES images is actually closer than the given times would indicate (the more precise time of the GOES scan across the central United States can also be noted for other comparisons given in the paper; for simplicity, the time indicated in each case is the start time of the scan).

These images view a good portion of the United States, which is covered by extensive cloudiness. Only the western part of the country is cloud free, where many terrain features, including mountain snow, can be readily identified in the DMSP image. These images enable a comparison of a large and very complex cloud system, some features of which are the following:

1) Large cells are embedded in the overall cloud mass in the Texas-Oklahoma area. These cells can be

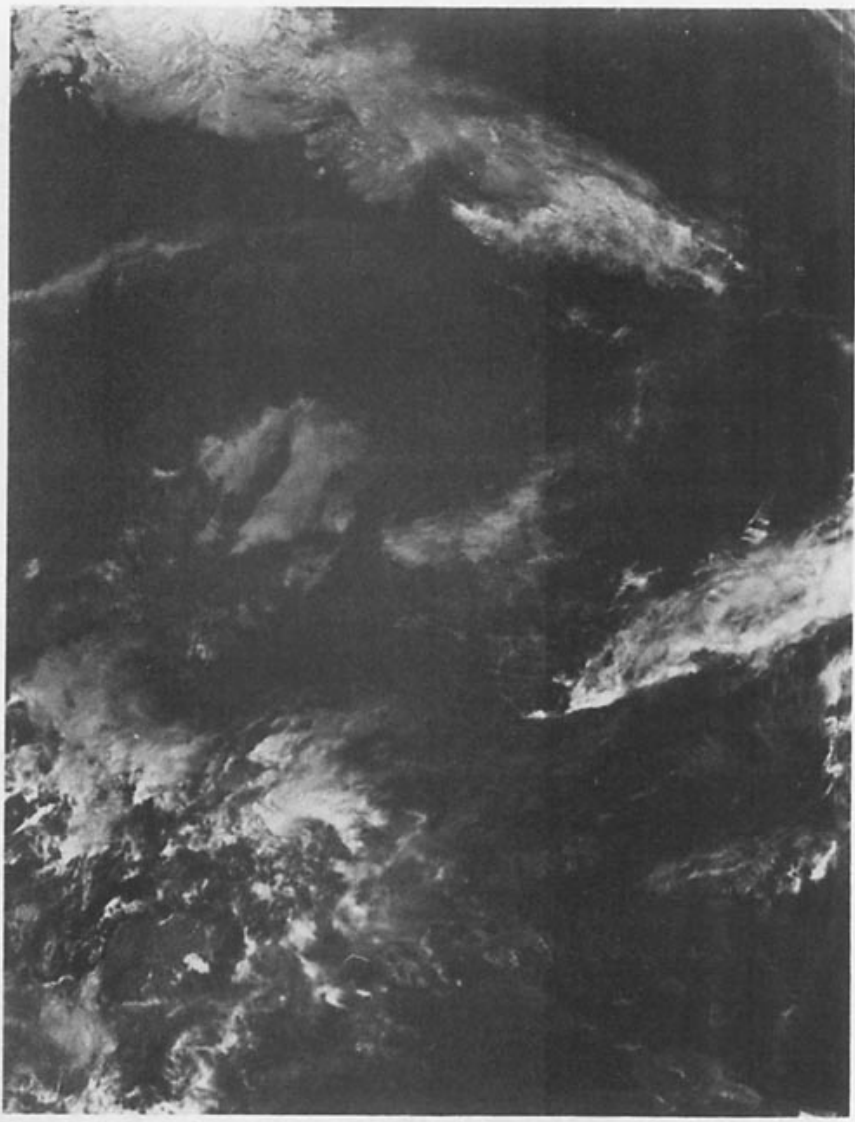

FIG. 3b. DMSP (LS) 1614 UTC 6 May-darker image.

detected in both images because of their shadows at the low sun angle, but they are much more distinct in DMSP. The area of the cells is very distinct from other clouds in the DMSP IR, but definition of individual cells is not possible, because the entire area appears saturated (Fig. 4b). The saturation in the DMSP IR image is probably the result of the more limited dynamic range of the sensor. The lower end of the DMSP IR channel dynamic range is about $210 \mathrm{~K}$, whereas the GOES dynamic range extends to at least $180 \mathrm{~K}$. The cloud-top temperatures in this case are probably lower than $210 \mathrm{~K}$ and therefore appear saturated in the DMSP image.

2) Cirrus bands extending from Mexico northeastward over the United States are visible in both DMSP and GOES. The fine detail of these bands, such as transverse waves, can be identified in the DMSP image. Both of the IR images give excellent definition of these bands over the lower (warmer) cloud, although the depiction is considerably better in the DMSP IR, probably due to the better spatial resolution of the sensor.

3) Terrain features in the northern Rocky Mountain area can be identified in both the DMSP visible and IR images; these features are more difficult to detect in the GOES images because of the poor viewing angle. Moreover, the broader DMSP spectral response (extending to $1.1 \mu \mathrm{m}$ ) provides better definition of land- 


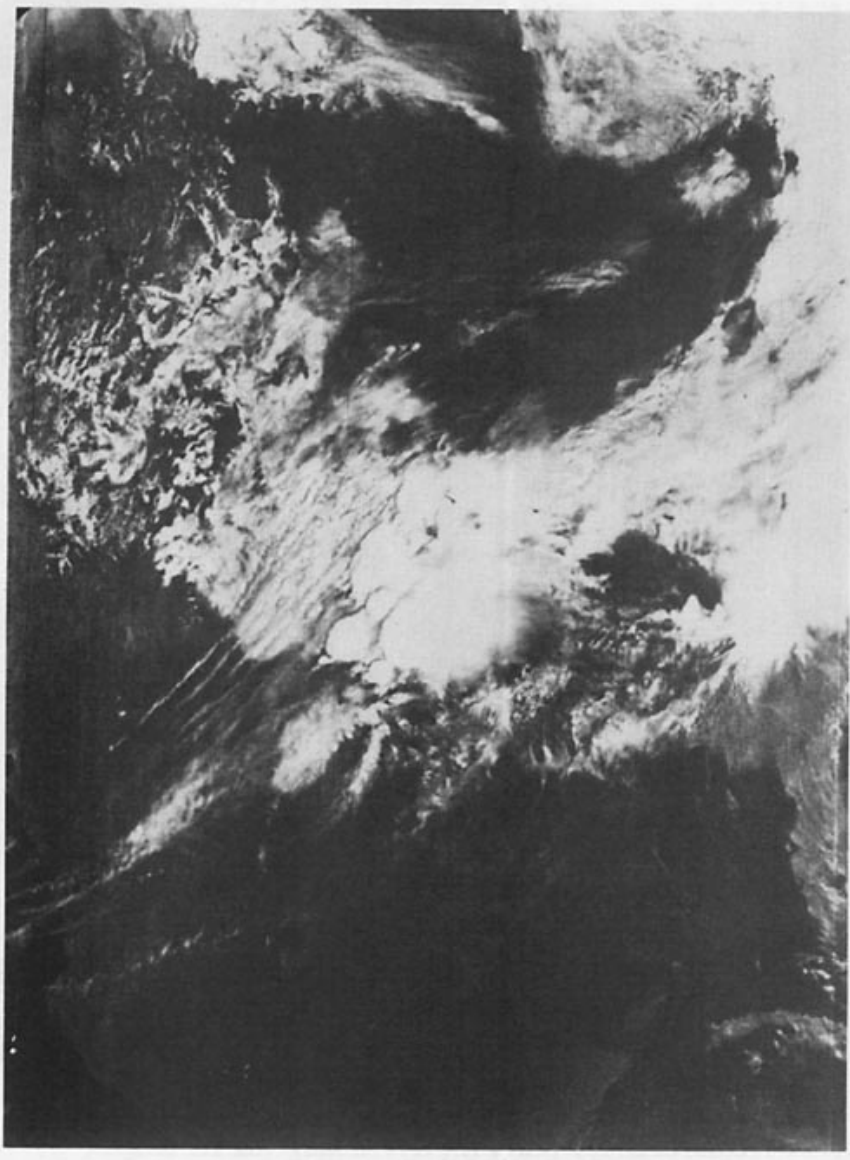

FIG. 4a. DMSP (LS) 1709 UTC 3 May.

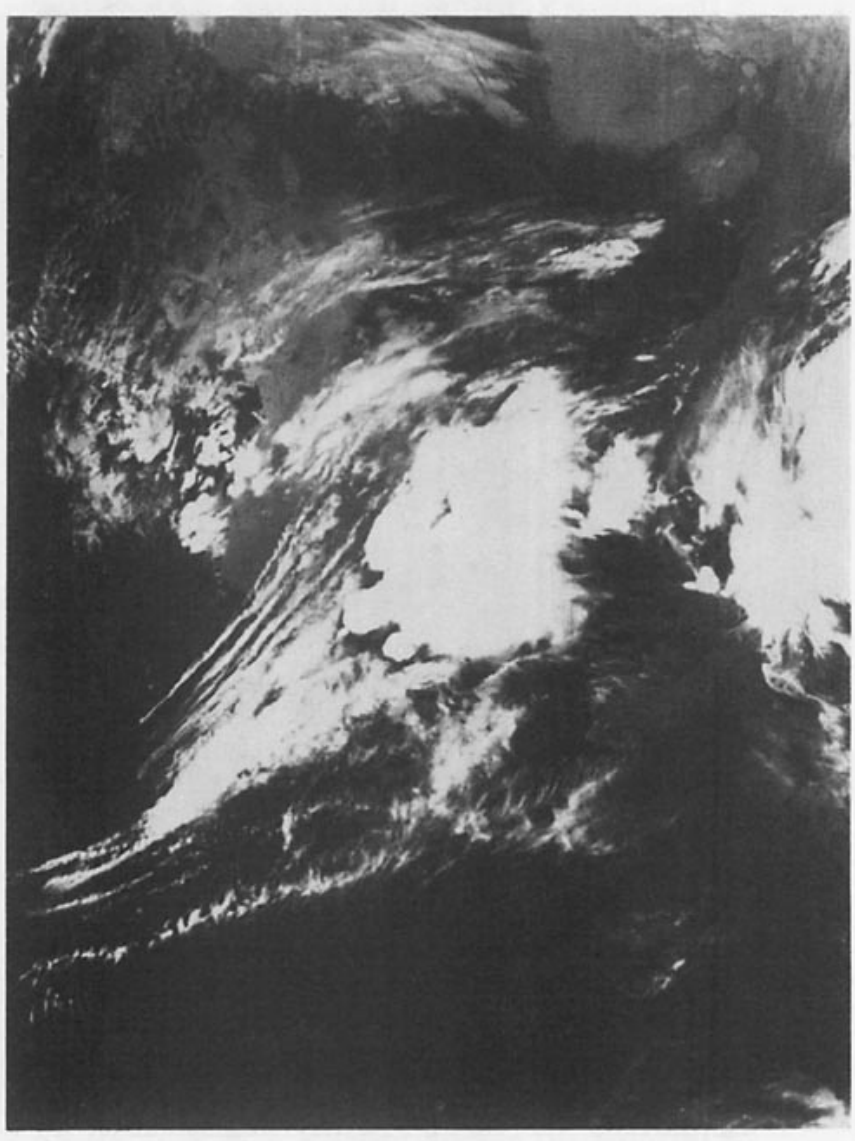

FIG. 4b. DMSP (TS) 1709 UTC 3 May. water boundaries than either GOES or NOAA AVHRR.

4) The cloud area over the southeastern United States to the east of the large cells has considerable detail that is distinct in DMSP but tends to be smoothed out in GOES.

NOAA AVHRR visible and IR images covering the western United States four and one-half hours later (2144 UTC) are shown in Figs. 6a and 6b. Since the NOAA prints are produced at a larger scale, two frames cover approximately the same area as one DMSP image (the frames shown here overlap with approximately the northwest quadrant of the corresponding DMSP images). Because of the time difference, individual cloud features have undergone considerable change, although the overall cloud patterns can be recognized. As with the GOES comparison, cirrus bands over the southwestern United States are particularly evident in the corresponding IR images (Figs. $5 \mathrm{~b}$ and $6 \mathrm{~b}$ ), both of which depict excellent definition of the high cirrus over lower cloud. Terrain features, such as the Great Salt Lake and mountain snow patterns, of course, remain stable and can be identified in both types of data. These features provide an indication of the comparative resolution and contrast of the NOAA and DMSP im- ages. Since these DMSP images are the smoothed-resolution data, the NOAA AVHRR resolution is better; the difference in resolution is evident when the images are compared. The NOAA images, however, are not corrected for edge distortion as are the DMSP images.

To illustrate the finer cloud and terrain detail in the DMSP fine-resolution data, a low sun angle DMSP LF image is shown in Fig. 7 (compare with Figs. 3 and 4a). This image has pronounced shadowing, which serves to enhance many of the cloud features (terrain shadowing can even be detected along the western edge of the image). Considerable information on the vertical structure within the large cloud mass over the central United States can be deduced from the cloud shadows; in fact, cloud shadows are a reasonably good way to estimate cloud height above the lower cloud or terrestrial surface. Another effect of the low sun angle is the pronounced sunglint along the eastern edge of the image, especially in the Florida area. The sunglint in combination with the shadowing appears to enhance small cloud elements over the ocean in that area. The analyst must also be aware of the reversal in reflectance caused by sunglint; water bodies in Florida appear bright against a darker background whereas some of the clouds over the water near Florida appear dark against a brighter background. 


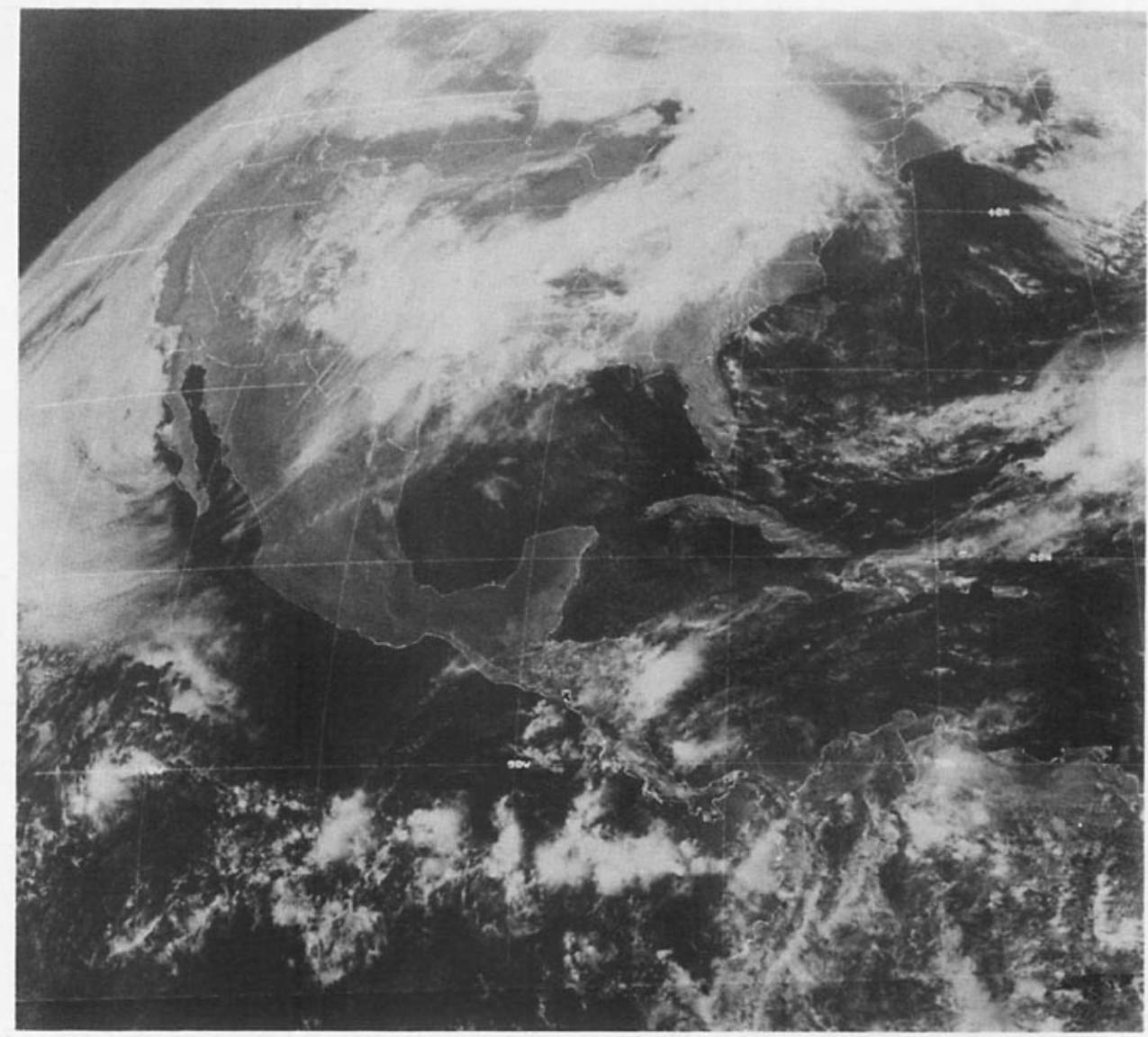

FIG. 5a. GOES (WB1 VIS) 1700 UTC 3 May.

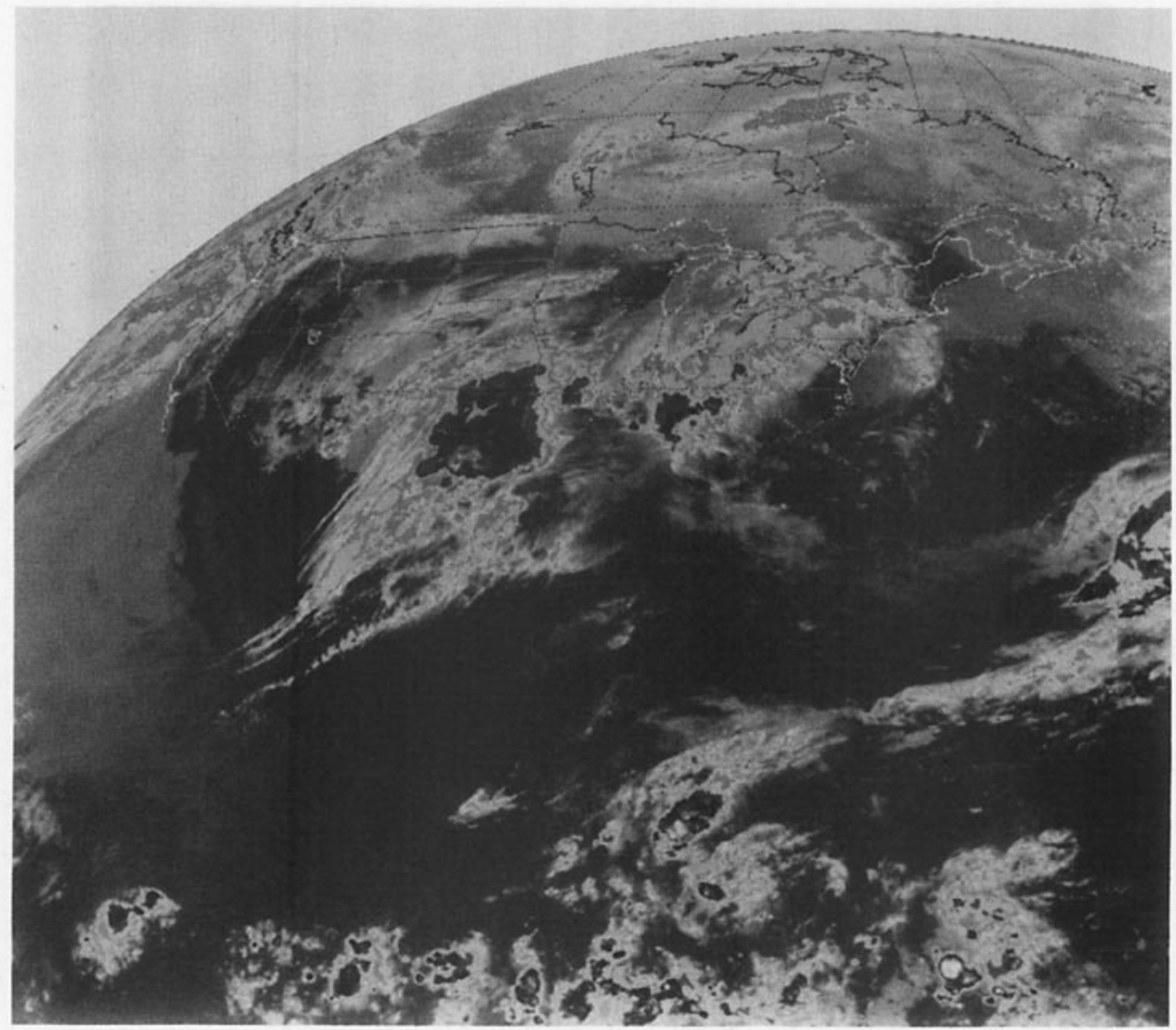

FIG. 5b. GOES (WB1 IR) 1700 UTC 3 May. 


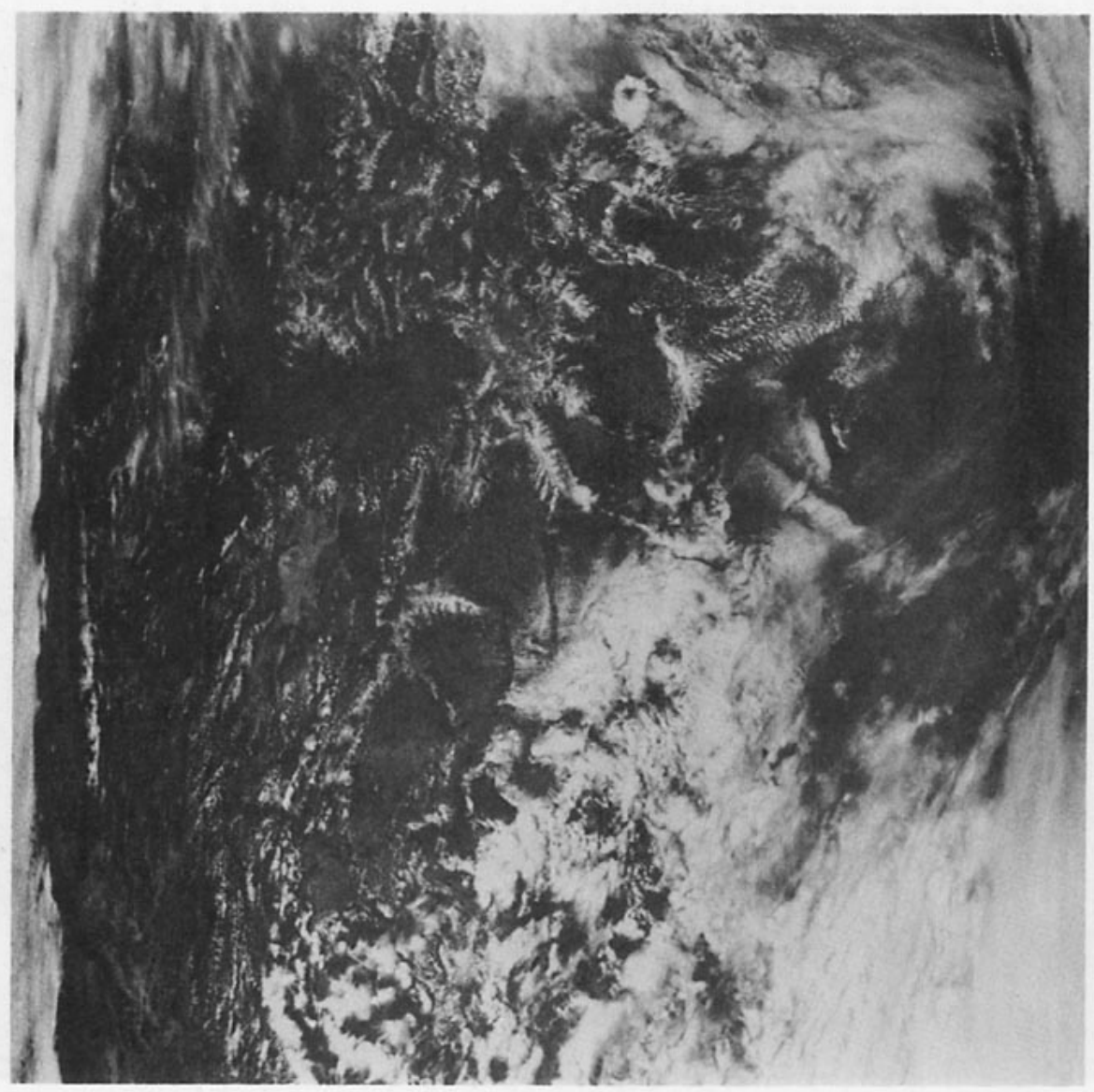

FIG. 6a. NOAA AVHRR (VIS) 2148 UTC 3 May.

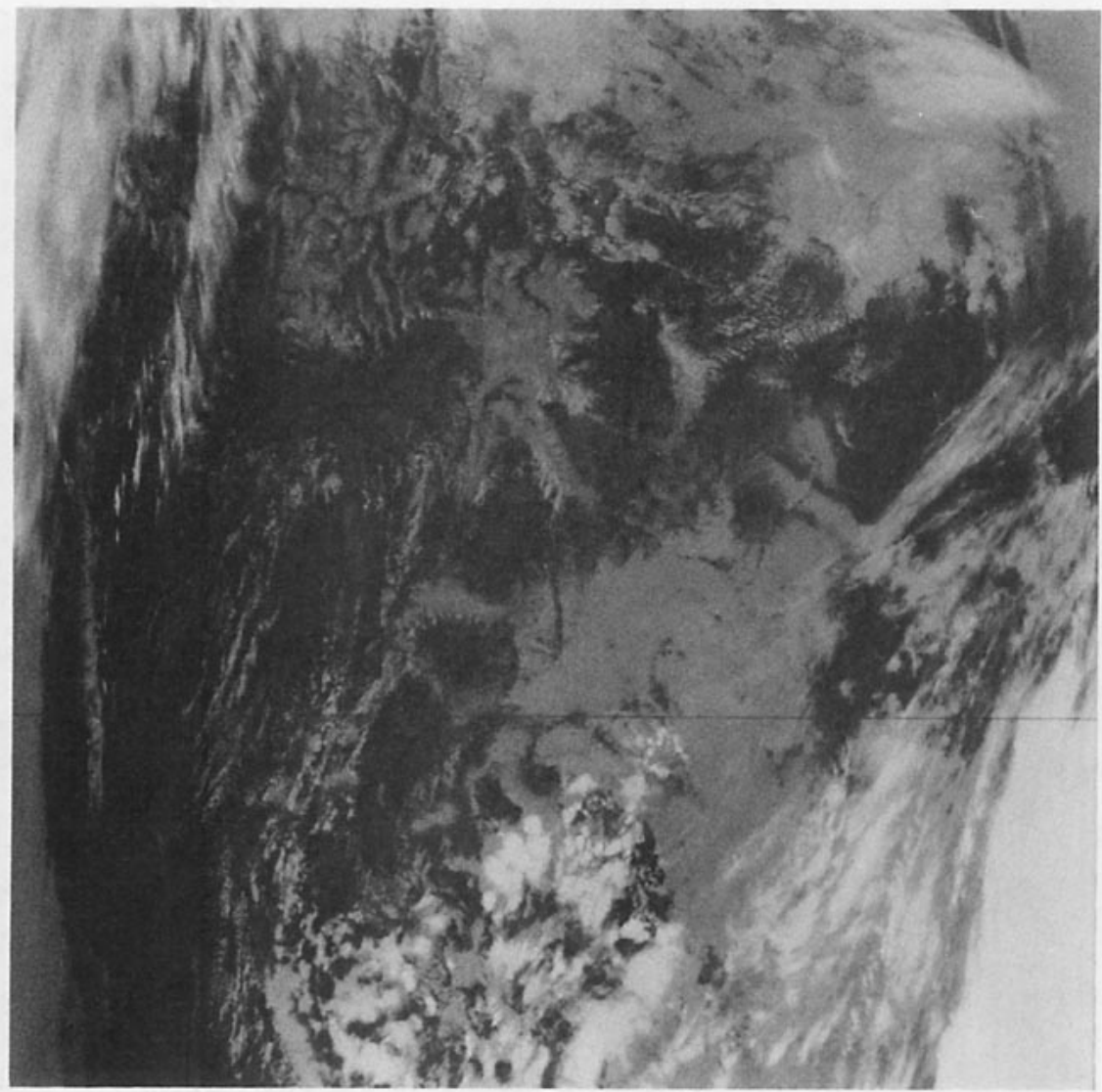

FIG. 6b. NOAA AVHRR (IR) 2148 UTC 3 May. 


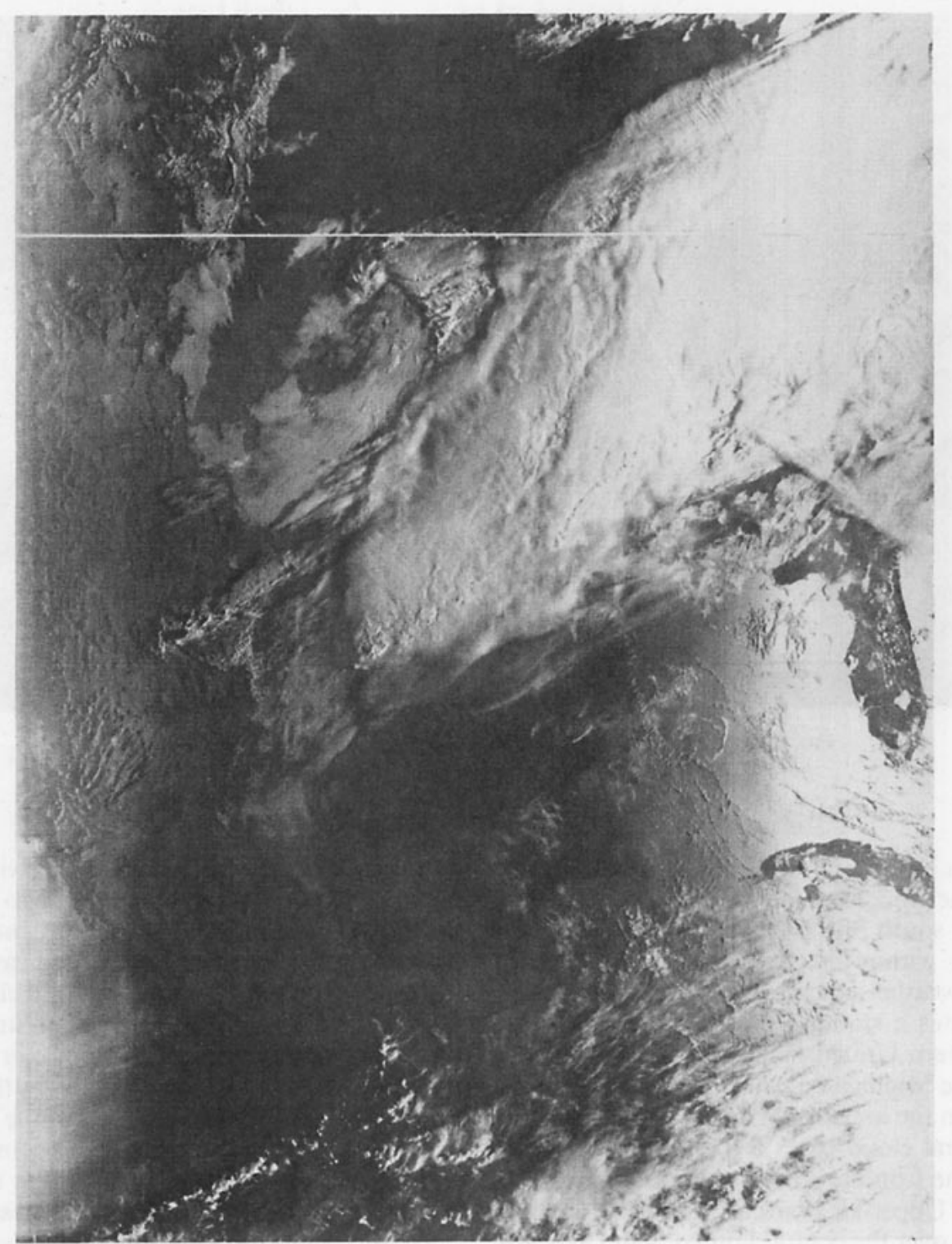

FIG. 7. DMSP (LF) 1229 UTC 4 May,

\section{c. Image intercomparison of cloud features in areas with Landsat coverage}

Landsat MSS imagery was acquired for some portion of the eastern United States on each of the four days of the May 1979 dataset discussed above. The Landsat coverage is, of course, very limited as compared to DMSP and GOES because of the narrow width of the Landsat swath. Image intercomparisons for two of the days are presented below. The data on 6 May provided the best opportunity to make use of the Landsat imagery because of the small time difference between the corresponding observations on that day. The only limitation to this dataset is that the DMSP image available at nearly the same time as the Landsat pass is the smoothed-resolution data.
A portion of the DMSP (LS) image at 1614 UTC, covering the northern United States, is shown in Fig. 8 (the full image is shown in Fig. 3a). Enlargements of GOES visible and IR images at 1600 UTC covering the northcentral United States, are shown in Figs. 9a and $9 \mathrm{~b}$. The GOES IR image indicates that the clouds over the southcentral United States that appear rather bright in the visible images are low-level stratus, whereas the cloud band across southern Lake Michigan is a band of high cirrus.

Landsat data were collected on this day (at 1611 UTC) on a pass just west of Lake Michigan. The area covered by three Landsat scenes on this pass is outlined on the DMSP and GOES images. The three Landsat MSS scenes (Band 5) are shown in Figs. 10a-c. The northernmost of the three scenes covers the southern 


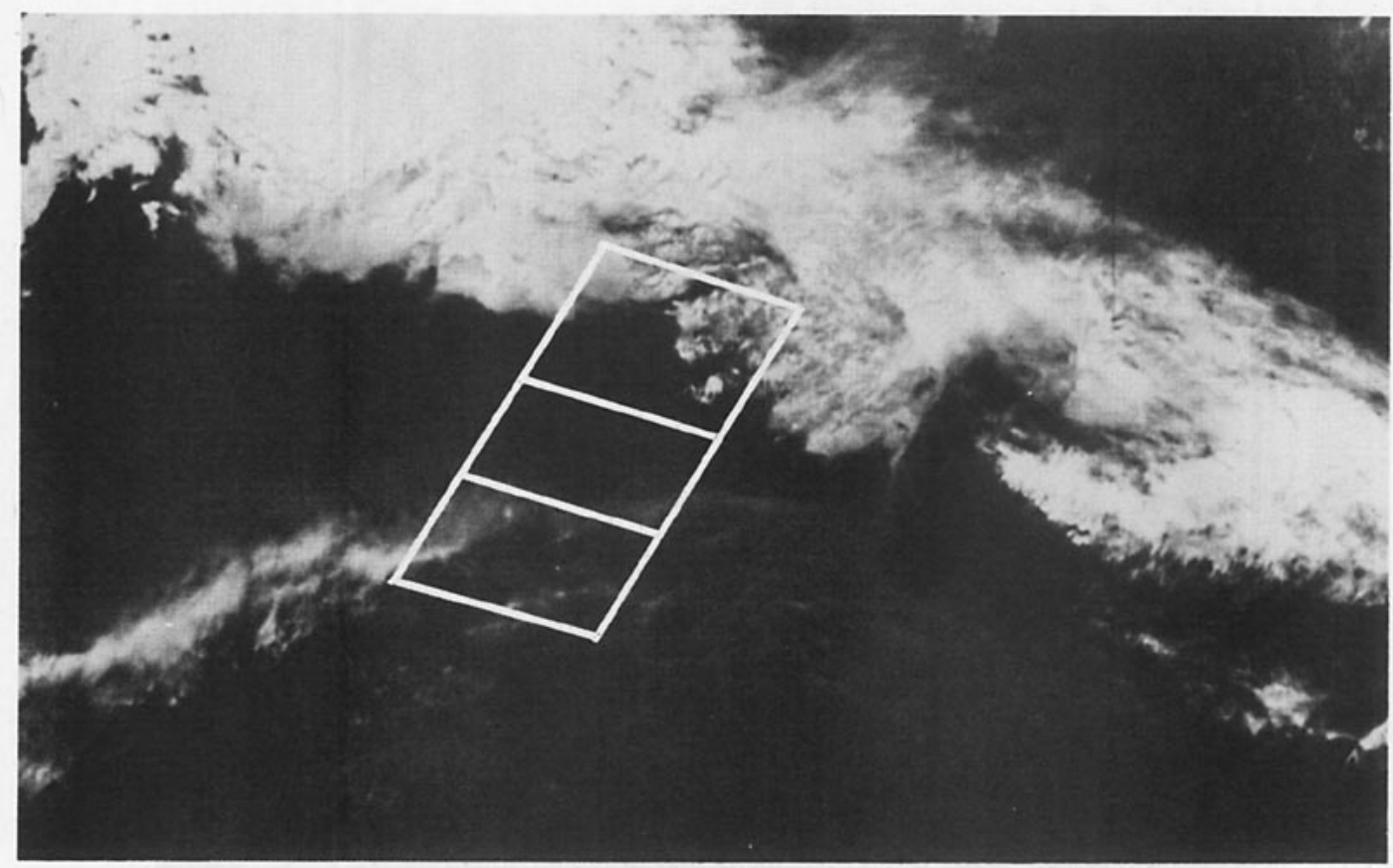

FIG. 8. DMSP (LS) 1614 UTC 6 May-portion enlargement (see Fig. 3a).

Area of corresponding Landsat coverage is outlined.

boundary of the broad east-west cloud area over the Great Lakes; the middle scene is at the edge of the cirrus band just south of the Great Lakes; the southernmost scene is within the cirrus band.

The surface weather chart at 1500 UTC on 6 May (Fig. 11) indicates a stationary front lying east-west across the northern United States. By 1800 UTC, the front in the Lake Michigan area is analyzed as a warm front. Stations in the area of Lake Superior report precipitation. Several cloud types are reported from stations north of the front; stations south of the front are reporting cirrus. Upper-air charts at 1200 UTC indicate a southerly flow over the central United States at lower levels $(850 \mathrm{mb})$ with dry air to the south and moisture over the northern Great Lakes. At the $500 \mathrm{mb}$ level, a trough is centered on the west coast with a broad area of west to southwesterly flow across the central United States. The strongest winds at the $500 \mathrm{mb}$ level appear to be in a band crossing the Great Lakes. An upperair sounding from a station in Minnesota located within the frontal cloud band shows considerable moisture at all levels up to nearly the $300 \mathrm{mb}$ level.

At approximately the time of the satellite observations, two reporting stations in Minnesota within the cloud-covered area (St. Cloud and Minneapolis) report ten-tenths stratus. Minneapolis, located at Point A in the Landsat scene (Fig. 10a), reports five-tenths stratocumulus (Sc), one-tenth altocumulus (Ac), and threetenths cirrus (Ci). Before the time of the Landsat pass, Minneapolis had been reporting ten-tenths Sc, and a couple of hours after the pass, reported a sky cover of one-tenth $\mathrm{Ac}$ and eight-tenths $\mathrm{Ci}$, with three-tenths opaque. These observations appear to fit closely with the cloud types deduced from the Landsat image. Assuming a cloud motion toward the east or northeast, Minneapolis was first under the solid cloud seen in the northeast portion of the image, then under the area of less solid cloud that appears to be Sc or Ac, and finally under an area of $\mathrm{Ci}$, which is likely the area of thin cloud seen in the westcentral part of the Landsat image. It must be remembered that when comparing satellite and surface cloud observations, high cloud amounts tend to be underestimated by the surface observer because of obscuration by lower clouds; the reverse is true for satellite observations.

The overall cloud features can be identified in the DMSP and Landsat images, but because of the greatly differing resolutions, some of the cloud elements seen in Landsat are difficult to detect in DMSP. The area of Sc/Ac in Fig. 10a cannot be seen, for example, in the DMSP image. In this instance, greater cloud detail can be seen in the enlarged GOES image (Fig. 9a) than in the DMSP image. The area of Sc/Ac just to the south of the solid cloud can be detected in GOES, and there is even an indication in GOES of the cloud area (Ac and $\mathrm{Ci}$ ) seen in the westcentral portion of the Landsat image just to the south of the Sc/Ac area. The cirrus band to the south is more evident in GOES than in DMSP and, of course, is well defined in the IR data. A puzzling aspect of this comparison among DMSP, GOES, and Landsat data is a relatively bright cloud that is very distinct in the middle Landsat scene (Fig. 


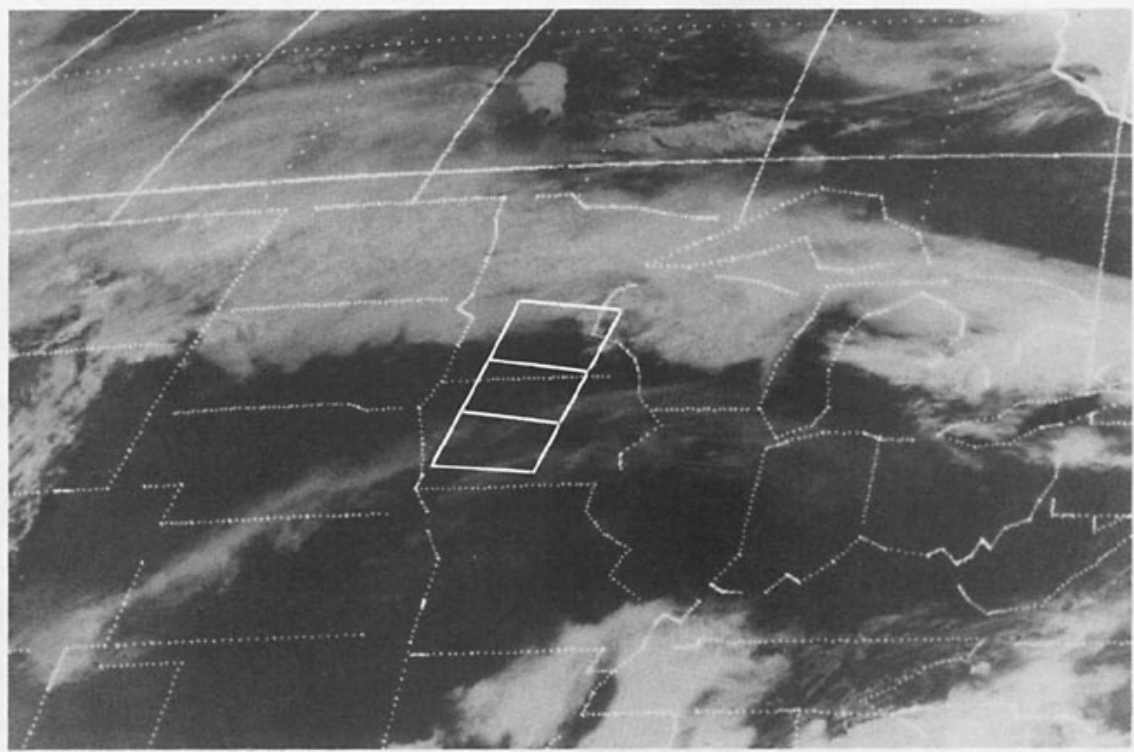

FIG. 9a. GOES (VIS) 1600 UTC 6 May-enlargement. Area of corresponding Landsat coverage is outlined.

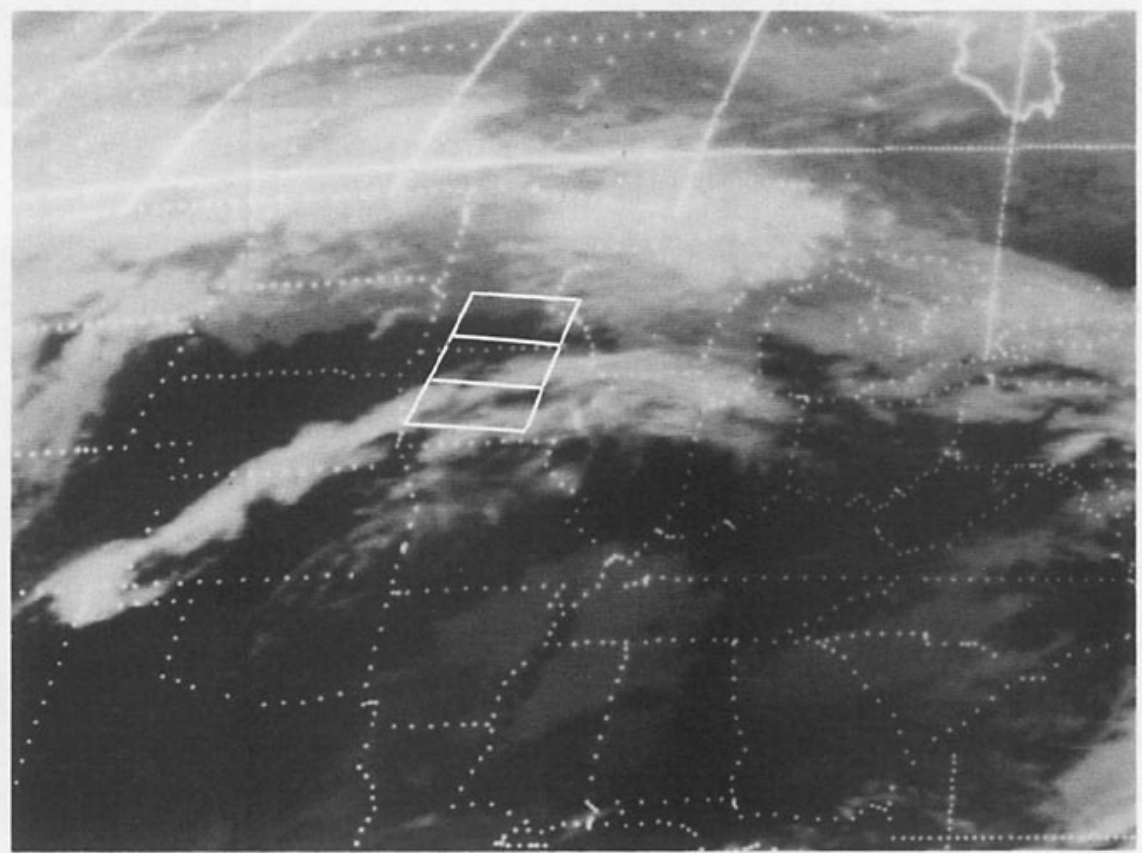

FIG. 9b. As in Fig. 9a except for GOES (IR).

10b) .but can barely be detected in the GOES image (Fig. 9a) and cannot be seen at all in the DMSP image (Fig. 8). This cloud feature, which is of the order of $10 \mathrm{~km}$ wide, appears to be lower cloud at the edge of the cirrus band. It is of sufficient size that it should certainly be seen in GOES and even in the DMSP smoothed data, particularly in view of the very small time differences between the observations. If the DMSP response was low enough to miss this cloud, then many other clouds would presumably be missed also. Perhaps the juxtaposition of the cloud with the cirrus band does not permit it to be distinguished separately in the lower resolution GOES and DMSP images. The differences in gain setting between Landsat and either DMSP or GOES (Landsat being set much lower because it is designed to view the earth's surface rather than clouds) 


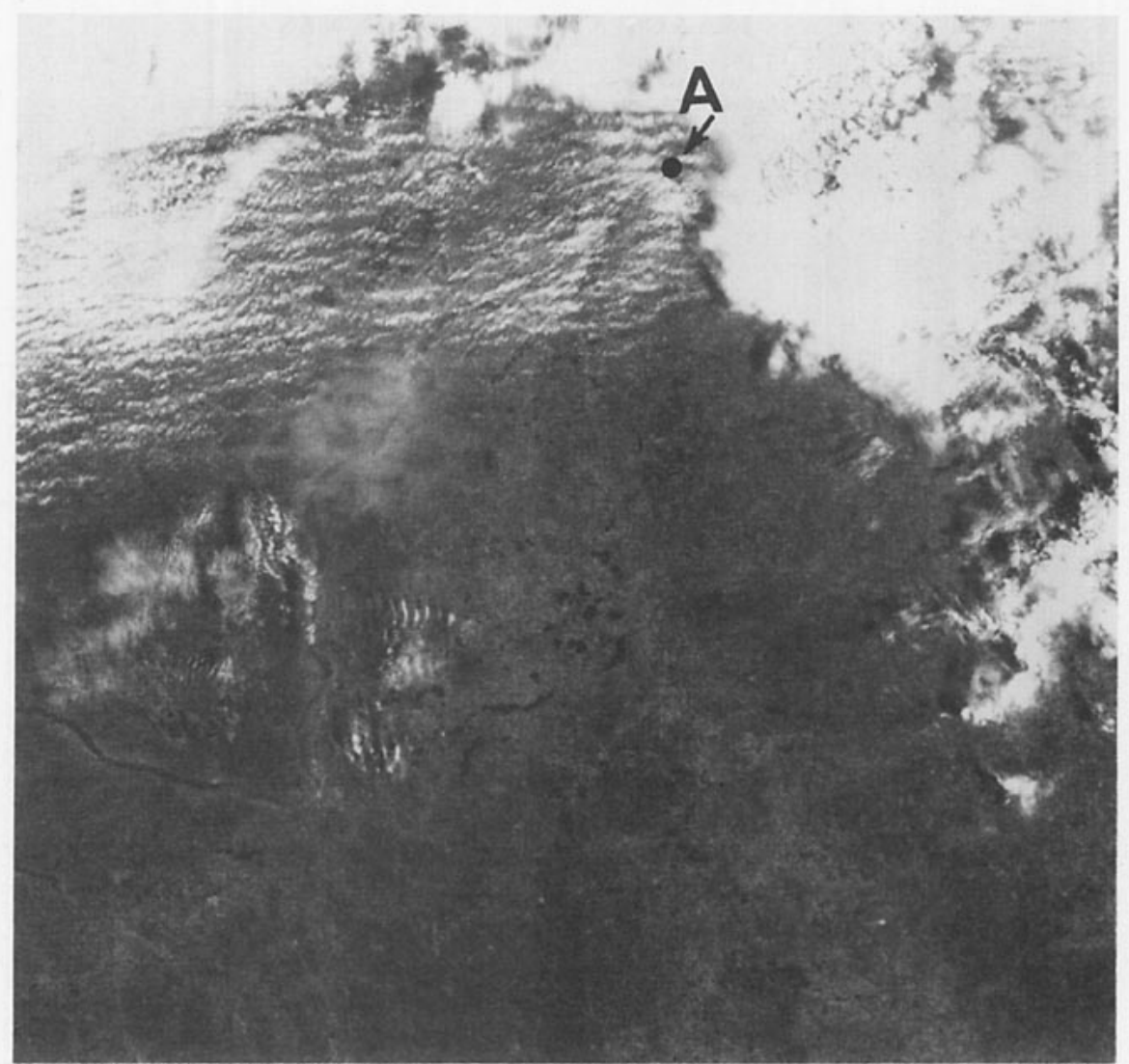

FIG. 10a. Landsat MSS Band 51611 UTC 6 May-scene (a). Reproduced by permission of EOSAT.

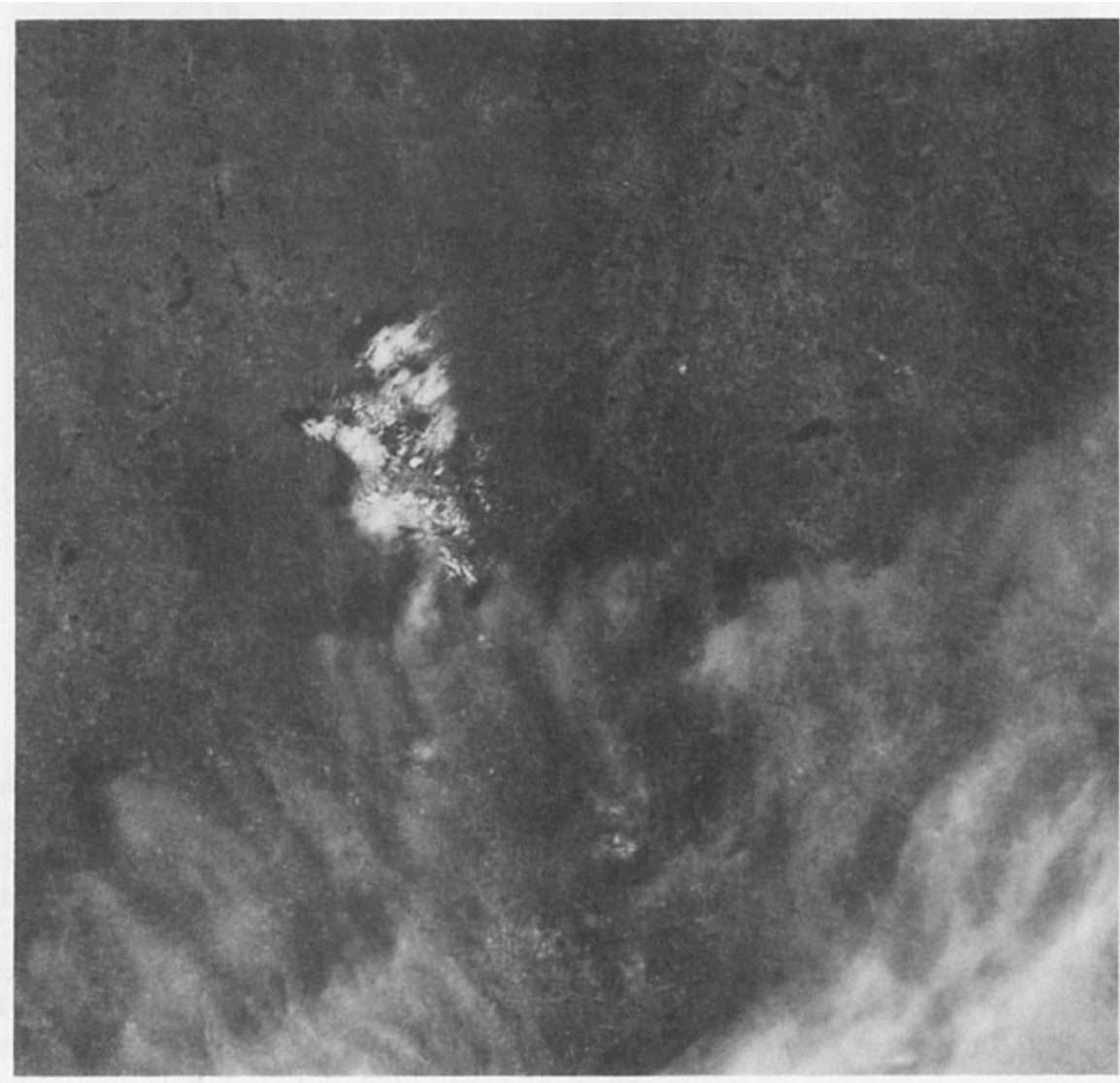

FIG. 10b. Landsat MSS Band 51612 UTC 6 May-scene (b). Reproduced by permission of EOSAT. 


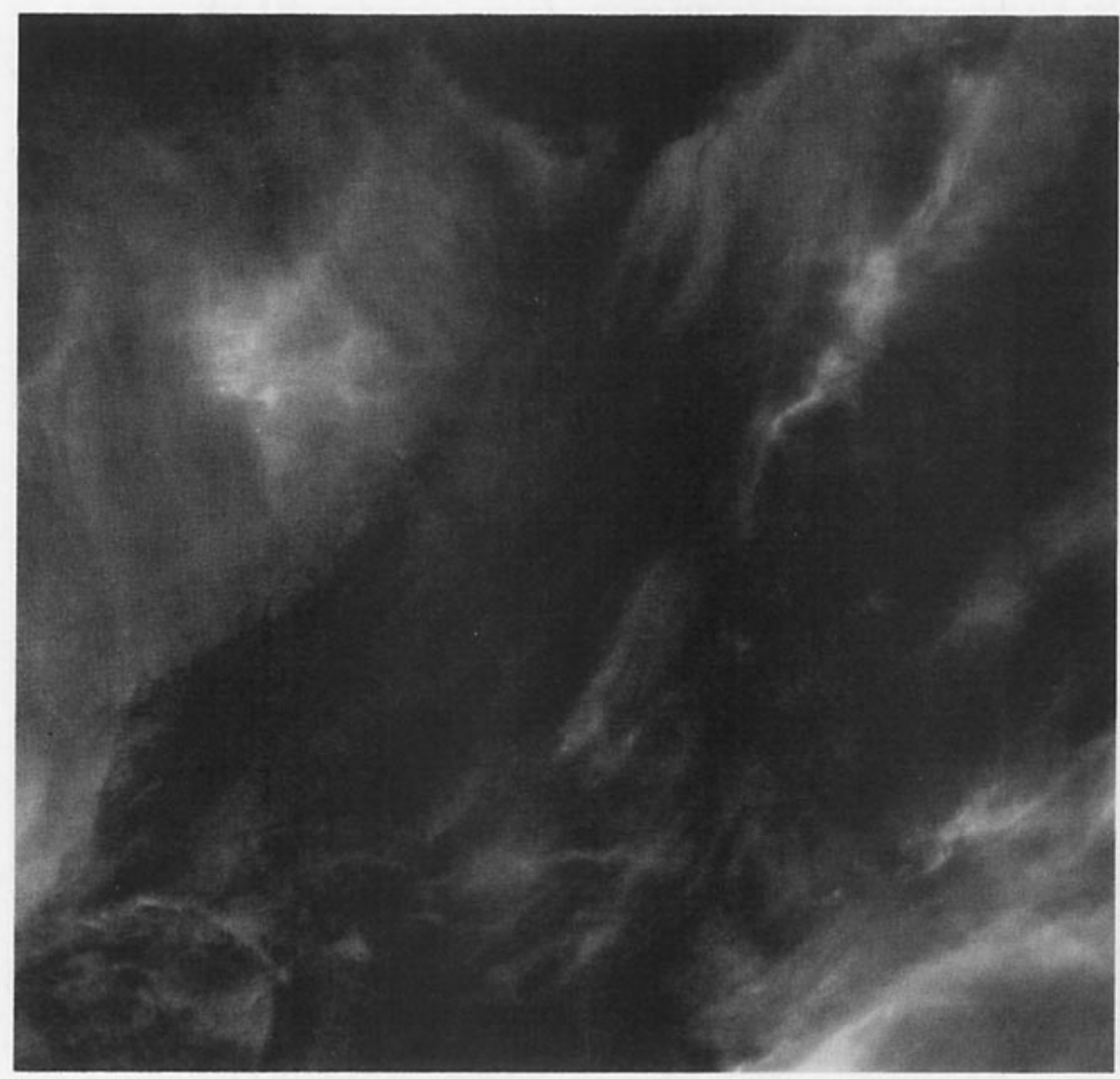

FiG. 10c. Landsat MSS Band 51612 UTC 6 May-scene (c). Reproduced by permission of EOSAT.

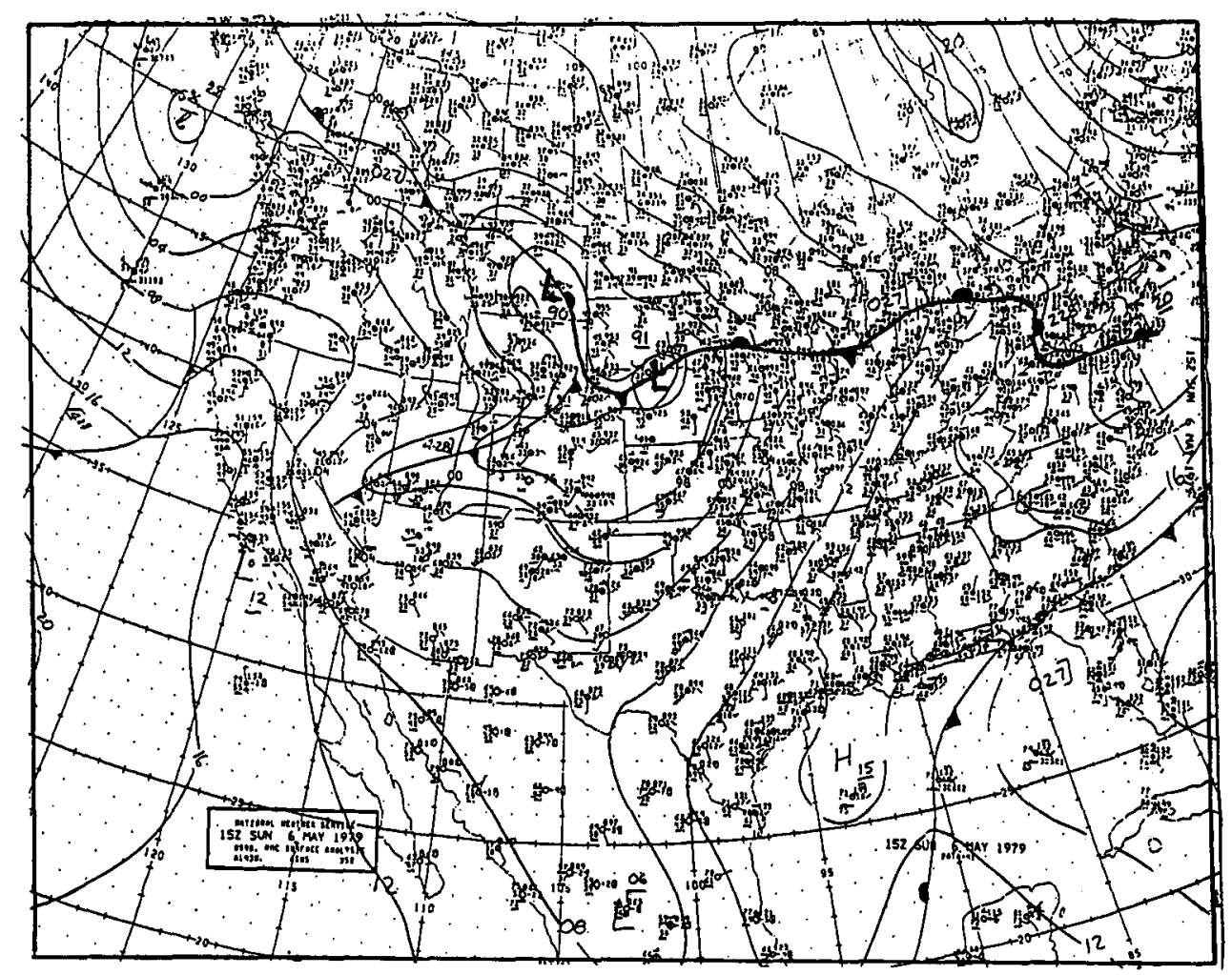

FIG. 11. Surface chart 1500 UTC 6 May. 


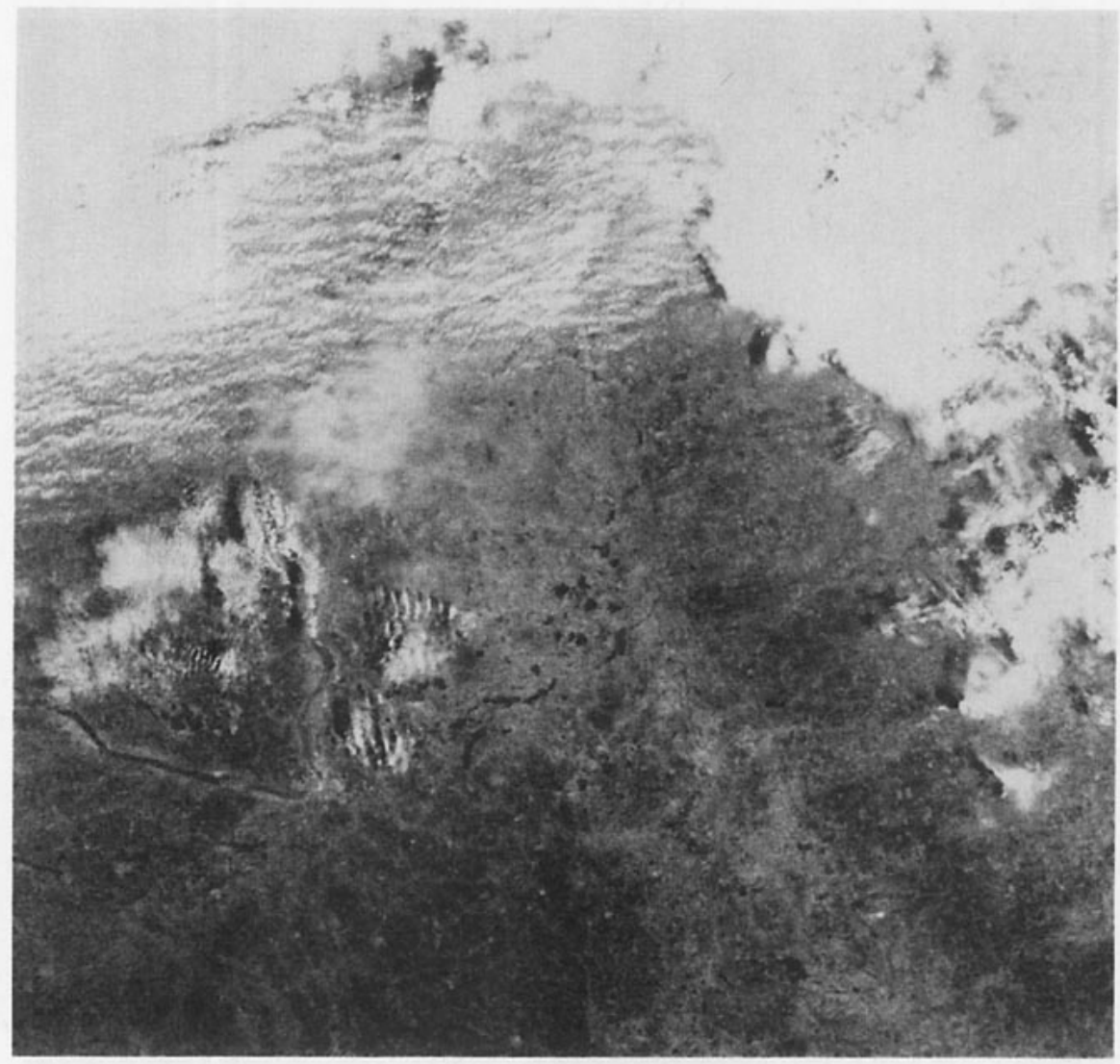

FIG. 12a. Landsat MSS Band 41611 UTC 6 May-scene (a). Reproduced by permission of EOSAT.

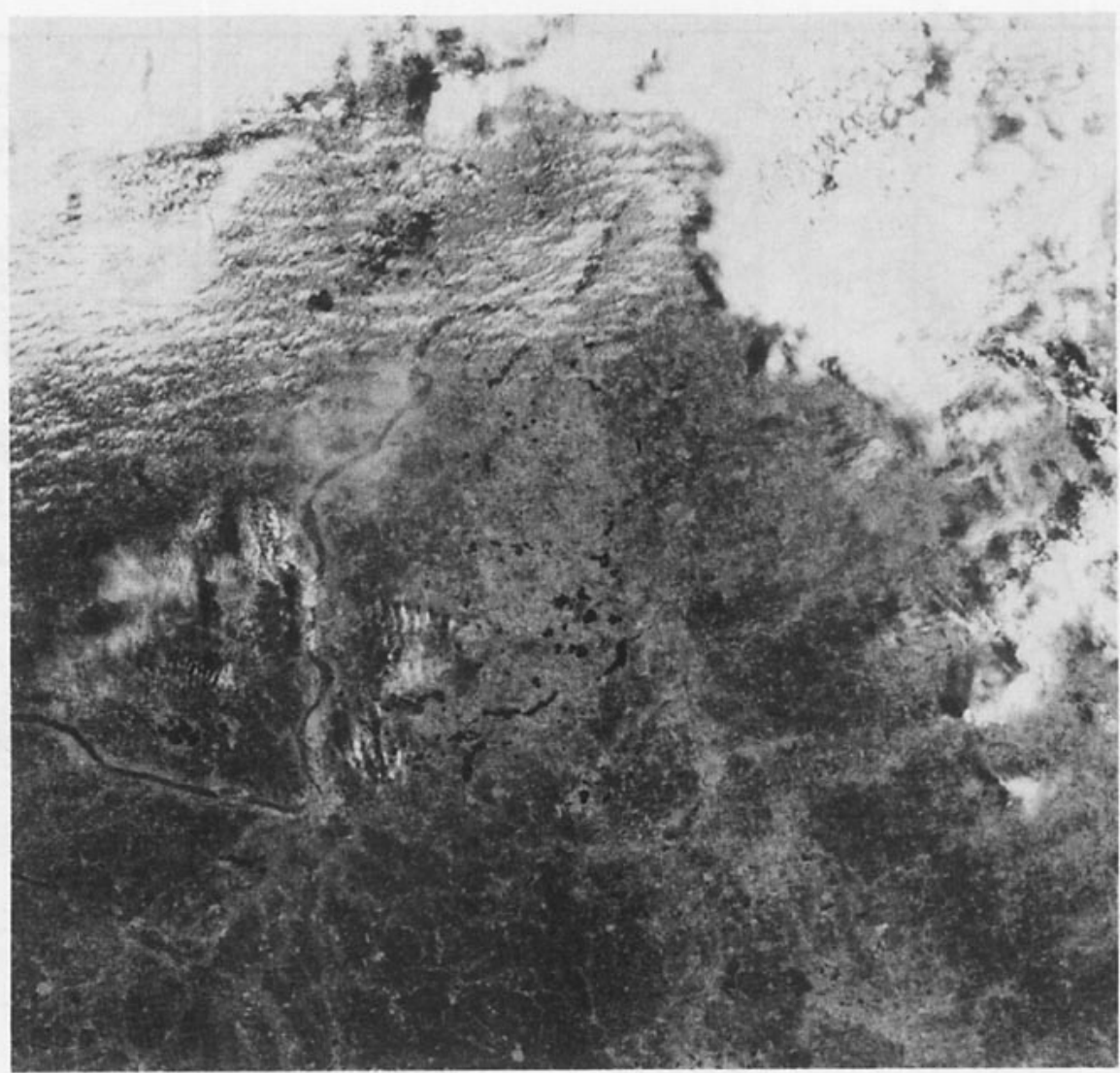

FIG. 12b. Landsat MSS Band 61611 UTC 6 May-scene (a).

Reproduced by permission of EOSAT. 


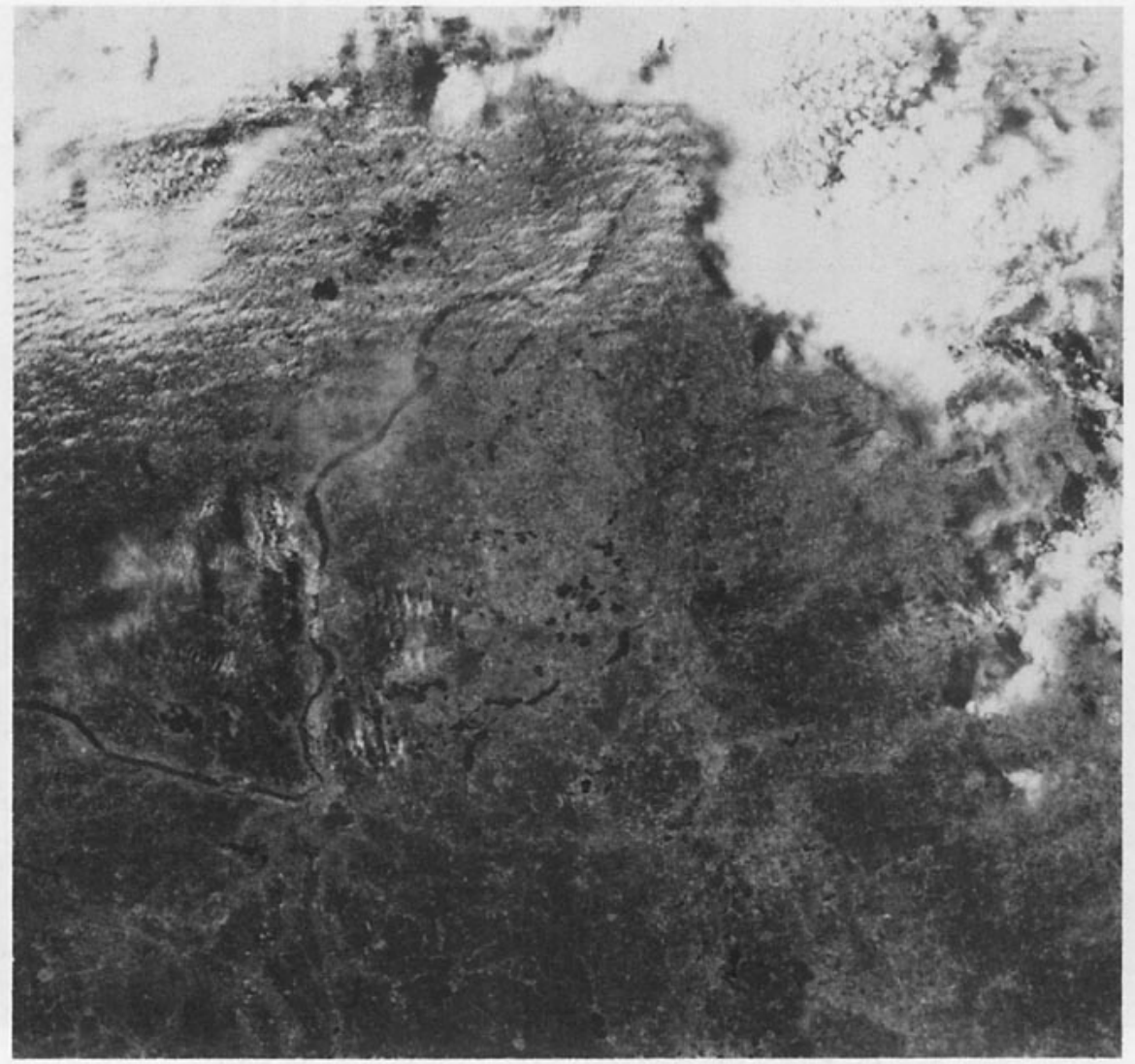

FIG. 12c. Landsat MSS Band 71611 UTC 6 May-scene (a). Reproduced by permission of EOSAT.

may be another reason why the cloud cannot be distinguished in the meteorological satellite images.

The Landsat images shown in Fig. 10 are all Band $5(0.6-0.7 \mu \mathrm{m})$. For the northernmost of these scenes, images for all four MSS bands were acquired; these additional bands are shown in Figs. 12a-c. In the Band 4 image (Fig. 12a), much of the cloud is saturated, but the areas of $\mathrm{Sc} / \mathrm{Ac}$ and $\mathrm{Ci}$ show up quite well. In Bands 6 and 7 (Fig. 12b and 12c, respectively), terrain features become more visible, with opaque water bodies in sharp contrast to the highly reflecting vegetation. The thinner clouds become more difficult to detect and appear much more transparent than in Bands 4 or 5 . In fact, an analyst would likely estimate a greater percentage of Sc/Ac cloud cover from Band 4 than from Band 7.

A Landsat image covering southwest Florida at almost the exact time (1517 UTC) as a GOES image (1500 UTC) provides another comparison of the effect of differing sensor spatial resolution. An enlargement of the GOES visible image showing the area covered by Landsat is shown in Fig. 13a; the Landsat Band 5 image is shown in Fig. 13b. At the time of these observations, Florida is completely covered by small cumulus cloudiness. The structure of the cumulus field is very evident in the Landsat image, including cells aligned in bands and the differing sizes of the cumulus cells. Areas of suppressed cloudiness over the western end of Lake Okeechobee and over two smaller water bodies to the north of the lake are evident. In the GOES image, the detailed structure of the cumulus field cannot be seen. However, even at the reduced GOES resolution, the two bays along the Florida west coast can be detected as can the inland areas of suppressed cloudiness (even the two smaller areas north of Lake Okeechobee). Also, there is an indication of the northwest-southeast orientation of the cumulus streets so clearly evident in the Landsat image and of the slightly brighter cloud in areas that are seen in the Landsat image to be areas of larger cumulus cells, such as just south of the small area of suppressed cloud north of Lake Okeechobee. The overall reflectance of the cumulus field over Florida in the GOES image is considerably less than that of the cloud areas to the north.

\section{Summary of results of imagery intercomparison}

Results of the imagery analysis are summarized below (these results pertain to visible imagery except where noted as being infrared); other examples can be found in the report by Isaacs et al. (1986). 


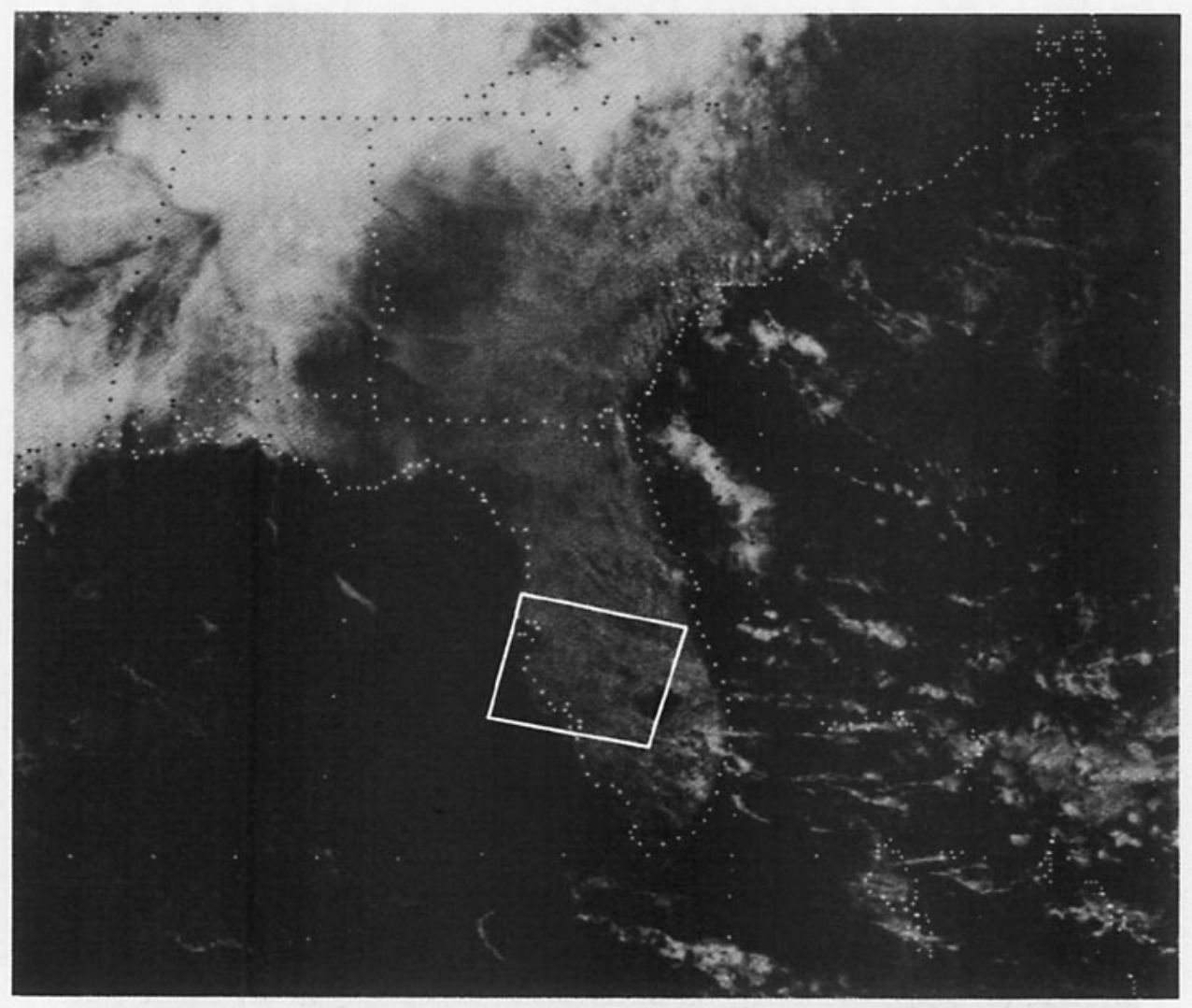

FIG. 13a. GOES VIS 1500 UTC 3 May-enlargement (Florida). Area of corresponding Landsat coverage is outlined.

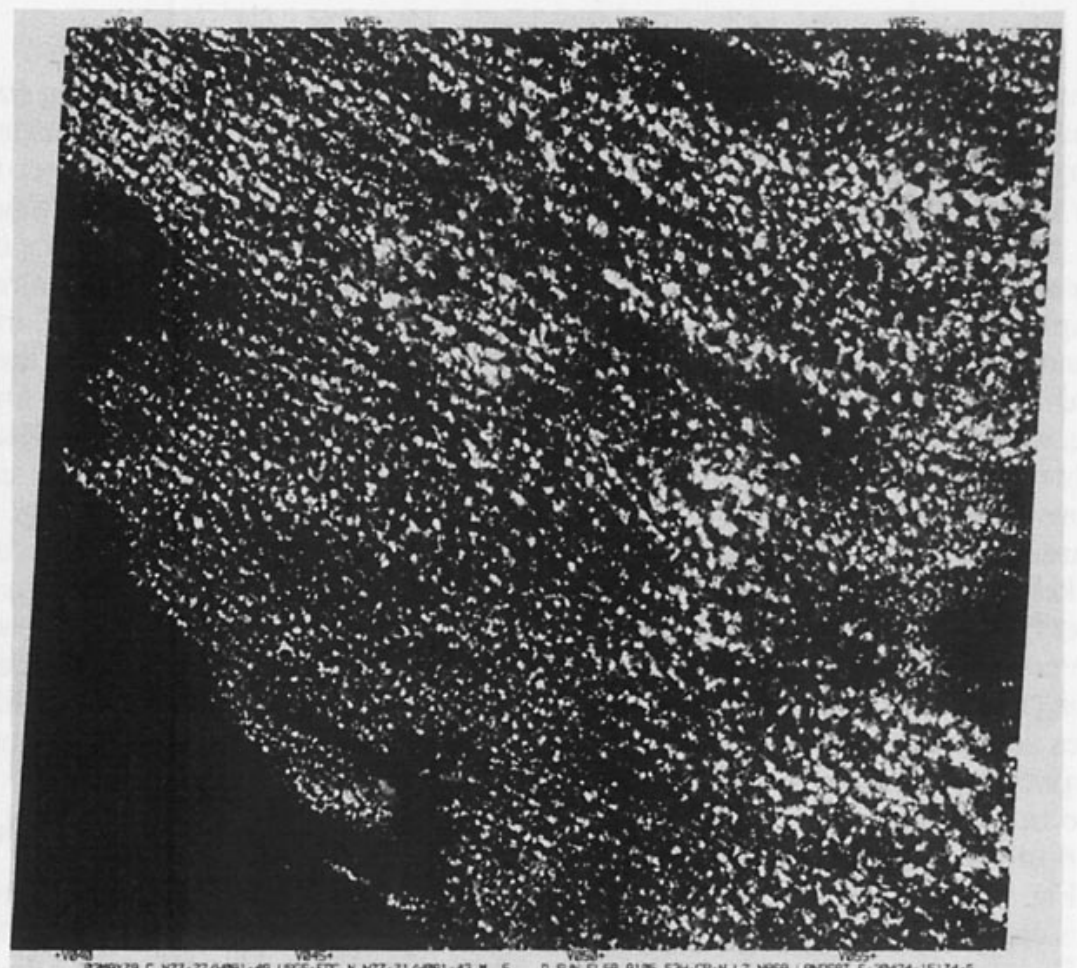

FiG. 13b. Landsat MSS Band 51517 UTC 3 May (Florida). Reproduced by permission of EOSAT. 


\section{a. GOES to DMSP}

- Many DMSP images are processed with high picture contrast. The high contrast results in saturation of some cloud features, especially extensive cloud areas, thus reducing detail in those areas. GOES images are processed at lower contrast, so even extensive, highly reflective cloud areas are not saturated.

- Terrain features can be seen in much greater detail in DMSP than in GOES images. The higher resolution of the DMSP fine-resolution data, the higher contrast of the images, and the broader spectral bandwidth of the DMSP OLS (extending into the near-IR) are all factors that may enhance terrain features. Except for coastlines and major inland water bodies, terrain features are not readily visible in the GOES images.

- Cloud shadows at low sun angles in DMSP images greatly enhance clouds with vertical development and high clouds over lower layers. Cloud shadowing is less pronounced in GOES images.

- At low sun angles, sunglint patterns may also be significant in DMSP images. Sunglint may obscure some clouds over the ocean because of reduced contrast between cloud and water but may also enhance some types of clouds such as tropical cumulus over water. Reversal in reflectance of water-land occurs in sunglint areas. Because of the viewing geometry, sunglint is not a problem in GOES images.

- Depiction of thin cirrus cloud may vary considerably depending on the processing of the image. Cloud that appears as thin cirrus in GOES may appear opaque in a high-contrast DMSP image; in other images, thin cirrus that is difficult to detect in GOES can be seen in DMSP.

- DMSP fine-resolution imagery provides considerably more detail of cloud edge features than GOES. Cumulus fields also have considerably more definition in DMSP than in GOES; in the lower-resolution GOES images (such as the WB1) cumulus fields generally appear as overall gray areas. Conversely, the highest resolution (sectorized) GOES visible images may depict more cloud detail than the somewhat lower resolution DMSP smoothed data.

- DMSP IR images tend to be saturated over large cloud masses; the enhancement curve used for the GOES IR data appears to display greater detail in those cloud areas.

\section{b. NOAA to DMSP}

- NOAA AVHRR and DMSP were difficult to intercompare, because the dataset did not provide concurrent observations. The NOAA images are displayed at a larger scale than DMSP but have edge distortion, which is removed in the DMSP images.

- The NOAA resolution is better than the DMSP smoothed resolution data. In one comparision where the corresponding observations were only three hours apart, the definition of a field of cumulus cells was better in the NOAA IR image than in the DMSP smoothed-resolution IR image; conversely, the definition in the DMSP fine-resolution visible image was better than in the NOAA visible image.

- The depiction of thin cirrus is usually better in NOAA visible imagery than in the high-contrast DMSP imagery.

- Because of similar orbital characteristics, the overall cloud depiction is quite similar in NOAA and DMSP imagery.

- Terrain features are better depicted in DMSP fine resolution imagery than in NOAA imagery probably due, at least in part, to the broader band pass of the OLS visible sensor.

\section{c. Landsat to DMSP}

- Individual cloud elements may be difficult to identify in corresponding Landsat and DMSP images because of the different resolutions and changes in clouds that occur over even relatively short time periods.

- Based on the limited sample of images examined, the cloud types and amounts deduced from Landsat imagery agree well with the cloud types and amounts reported by ground observers. Thus, at least for certain cloud types, it appears that Landsat could be used as a source of "ground truth" for evaluating meteorological satellite imagery.

- Although major cloud features can be identified in both types of imagery, the detail of the cloud edges seen in Landsat cannot be seen in DMSP smoothed resolution imagery; the fine-resolution imagery compares much better with Landsat, especially when terrain features are visible for use as reference points.

- Because of a gain setting for viewing the ground rather than clouds, Landsat images saturate quickly over large cloud masses.

- Thin cirrus cloud that may be difficult to detect in DMSP can be readily detected in Landsat. Moreover, at the Landsat resolution, a considerable amount of information on the structure within the cirrus cloud is apparent.

- Considerable variation in cloud depiction is observed over the four Landsat MSS spectral bands. Thin cloud is much better depicted at the shorter wavelengths (Bands 4 and 5), but cloud saturation is a greater problem; at the longer wavelengths (Bands 6 and 7), penetration through thin cloud is substantially greater than at the shorter wavelengths.

- In one set of concurrent observations, a small cloud feature that appears very bright in Landsat cannot be detected at all in the smooth-resolution DMSP; it may be simply that the smooth-resolution DMSP data are too coarse to resolve the feature.

\section{d. Landsat to GOES}

- It is difficult to compare the North American (WB1) GOES image with Landsat because of the great 
differences in scale and resolution. A meaningful comparison can be carried out, however, using enlargements of the areas of interest in the GOES images.

- In one dataset examined, features seen in Landsat could be identified better in the corresponding GOES image than in the DMSP smooth-resolution image. An area of cirrus was better defined in GOES and a small cloud feature that could not be detected at all in DMSP could be seen in GOES.

- Some of the overall structure of a cumulus field over Florida could be detected in an enlarged GOES image, although the individual cells seen clearly in the concurrent Landsat image were not resolved by GOES.

- The percentage of cloud amount within the area of a Landsat scene estimated from Landsat and from GOES or DMSP imagery could vary considerably depending on cloud type. The analyst might arrive at similar cloud percentages if the scene contains a welldefined cloud edge; however, with a broken field, a "fuzzy" cloud edge, or thin cirrus cloud, the estimated cloud percentage could be quite different between Landsat and either DMSP or GOES.

\section{Conclusions}

This paper has presented the results of a study to develop methods to aid in the interpretation of clouds from different imaging sensors based on experience gained from the analysis of actual image datasets. The sensors of interest were the DMSP OLS, the NOAA AVHRR, the GOES VISSR, and the Landsat MSS. A unique dataset has been assembled, consisting of approximately 50 individual images covering the eastern United States in early May 1979. This dataset offers the capability to examine distinctive cloud features as concurrently as possible from the four satellite systems. As pointed out in the discussion, the imagery intercomparisons are qualitative in nature because of the many factors that influence the processing and display of photographic products. Nevertheless, images in the formats shown are typically used in analysis and forecasting, and the intercomparisons can provide guidelines for the analyst to assist in the correct interpretation of imagery from the different satellite sensors.

The results of the imagery analysis indicate that sensor resolution and spectral response are both important considerations for correct image interpretation. Because of the broader bandwidth of the OLS, for example, terrain features are much more prominent in DMSP than in GOES; with regard to resolution, the DMSP fine-resolution (F) data show significantly more detail than either the GOES or NOAA AVHRR data. Other orbital characteristics can be important, especially with regard to sunglint and shadowing, which can obscure some cloud features but greatly enhance others. The photographic contrast with which the images are processed can also be critical for correct interpretation of certain cloud features, such as thin cir- rus. GOES of course offers the advantage of providing time lapse cloud observations; the cloud motions derived from sequential GOES images can be a major asset in distinguishing cloud type information.

For at least certain types of clouds, Landsat can provide a source of "ground truth" cloud information for comparing the other types of satellite imagery (keeping in mind the infrequency of Landsat repeat coverage and the fact that Landsat images saturate quickly over large cloud masses). The appearance of cloud and terrain features in the four MSS spectral band images can be useful for interpreting the broader band images from the other sensors. Further study of Landsat imagery could be very helpful in developing improved methods to interpret thin cirrus cloud, which remains a problem in satellite image analysis.

Although image interpretation will continue to be an important analysis tool, the development of automated, interactive processing systems will eventually lead to greatly improved, quantitative analysis techniques. Some of the data used in this study have also been acquired in digital format to study the feasibility of machine-based digital data intercomparison and transformation. Initial results are encouraging; however, much remains to be done to refine these quantitative techniques and apply them to practical and operational problems. Ultimately, such tools could be applied operationally to provide a digital data formatter that would interface between available sensor datasets and automated cloud analysis algorithms, such as the Air Force RTNEPH, which is highly tuned for a specific sensor system (DMSP).

Acknowledgments. The authors thank Rupert S. Hawkins and Dr. Kenneth R. Hardy of the Air Force Geophysics Laboratory for their help and encouragement. Landsat imagery is reproduced by permission of EOSAT. The NOAA and GOES data were obtained from NOAA/NESDIS/NCDC and the DMSP imagery from the Cooperative Institute for Research in Environmental Sciences at the University of Colorado.

This work was sponsored by the Air Force Geophysics Laboratory, Hanscom Air Force Base, MA, under Contract F19628-85-C-0102.

\section{REFERENCES}

Barnes, J. C., R. G. Isaacs, C. J. Bowley and A. J. Bussey, 1979a: Comparative Study of Anomalous Gray-Scale Patterns in DMSP and Landsat Imagery. Final Report Contract N00228-77-G3164, Naval Environmental Prediction Research Facility, ERT, Inc., Concord, MA.

- C. J. Bowley and H. K. Burke, 1979b: Evaluation of the Capabilities of Satellite Imagery for Monitoring Air Pollution Episodes. NASA CR-159197, Langley Research Center.

,,-- M. D. Smallwood and J. H. Willand, 1981: The Application of Heat Capacity Mapping Mission (HCMM) Thermal Data to Snow Hydrology. Final Rep. Contract No. NAS5-24316, NASA/GSFC, ERT, Inc., Concord, MA, 99 pp.

Bowley, C. J., J. C. Barnes and A. Rango, 1979: Satellite Snow Mapping and Runoff Prediction Handbook. Final Report Contract 
NAS5-24410, NASA Goddard Space Flight Center, ERT, Inc., Concord, MA, 87 pp.

Brandli, H. W., 1976: Satellite Meteorology. AWS/TR-76-264, USAF AWS, Scott AFB, IL, 203 pp. [NTIS No. AD-A067090.]

Bunting, J. T., R. S. Hawkins and R. P. d'Entremont, 1983: R and D nephanalysis at the Air Force Geophysical Laboratory. Fifth Conf. on Atmospheric Radiation, Baltimore, Amer. Meteor. Soc.

Cornillon, P. C., 1982: A Guide to Environmental Satellite Data. University of Rhode lsland, Marine Tech. Reprint 79, Narragansett, RI.

Dismachek, D. C., A. L. Booth and J. A. Leese, 1980: National Environmental Service Catalog of Products, Third Edition. NOAA Tech. Memo, NESS 109, Washington, DC.

Engel, J. L., and O. Weinstein, 1983: The thematic mapper-an overview. IEEE Trans. Geosci. Remote Sens., GE-21, 258-265.

Feteris, P. J., A. S. Lisa, C. J. Bowley, M. G. Fowler and J. C. Barnes, 1976: Investigation of Mesoscale Cloud Features Viewed by LANDSAT. Final Report Contract NAS5-20804, NASA/GSFC, ERT, Inc., Concord, MA, 76 pp.

Fett, R. W., and R. G. Isaacs, 1979: Concerning causes of "anomalous gray shades" in DMSP visible imagery. J. Appl. Meteor., 18, 1340 .

- , and W. F. Mitchell, 1977: Navy Tactical Applications Guide: Vol. 1, Technique and Applications of Image Analysis (DMSP). NEPRE Applications Rep. 77-03, Tactical Applications Department, Naval Environmental Prediction Research Facility, Monterey, CA.

Haig, T. O., 1982: The Role of Meteorological Satellites in Tactical Battlefield Weather Supp. AFGL-TR-82-0124. [NTIS ADA 1693616]

Hughes, N. A., and A. Henderson-Sellers, 1985: Global 3D nephanalysis of total cloud amount: Climatology for 1979. J. Climate Appl. Meteor., 24, 669-686.

Isaacs, R. G., J. C. Barnes, L. D. Petro and R. D. Worsham, 1986: Intercomparison of DMSP OLS, NOAA AVHRR, GOES
VISSR, and Landsat MSS Imagery for Cloud Property Determination: Recommendations for Digital Data Analysis. AFGL TR-86-0012. [NTIS ADA169285141 XAB]

Kaehn, A. J., Jr., 1982: Military applications evolution and future. The Conception, Growth, Accomplishments, and Future of Meteorological Satellites, NASA CP 2257, 41-47.

NASA, 1982: Landsat Data Users' Notes (No. 23). U.S. Geological Survey, EROS Data Center, Sioux Falls, SD.

NOAA, 1981: NOAA polar orbiter data (TIROS-N and NOAA-6) users' guide. NOAA-EDIS-NCC-SDSD, Washington, DC.

Rivers, J. W., Jr., and C. P. Arnold, Jr., 1982: Defense meteorological satellite program (DMSP). Meteorological Satellites-Past, Present, and Future. NASA CP 2227, 31-34.

Santa Barbara Research Center, 1978: System description (revision b): Visible infrared spin scan radiometer. Rep. to NASA under Contract NAS5-20769.

Schiffer, R. A., and W. B. Rossow, 1983: The International Satellite Cloud Climatology Project (ISCCP): The first project of the World Climate Research Programme. Bull. Amer. Meteor. Soc., 64(7), 779-784.

$\longrightarrow$, and - 1985: ISCCP global radiance dataset: A new resource for climate research. Bull. Amer. Meteor. Soc., 66(12), 14981505.

Schwalb, A., 1978: The TIROS-N/NOAA A-G Satellite Series. NOAA TM NESS 95, U.S. Dept. of Commerce, Washington, DC.

Shenk, W. E., and V. V. Salomonson, 1972: A simulation study exploring the effects of sensor spatial resolution on estimates of cloud cover from satellites. J. Appl. Meteor., 11, 214-220.

-, T. H. Vonder Haar and W. L. Smith, 1987: An evaluation of observations from satellites for the study and prediction of mesoscale events and cyclone events. Bull. Amer. Meteor. Soc., 68(1), 21-35.

Spangler, M. J., 1974: The DMSP primary data sensor. Proc. Sixth Conf. on Aerospace and Aeronautical Meteorology, El Paso, Amer. Meteor. Soc., 150-157. 